\title{
Influence of abiotic stresses on plant proteome and metabolome changes
}

\author{
Paweł Rodziewicz $\cdot$ Barbara Swarcewicz $\cdot$ \\ Klaudia Chmielewska • Anna Wojakowska • \\ Maciej Stobiecki
}

Received: 14 August 2013/Revised: 25 September 2013/Accepted: 2 October 2013/Published online: 18 October 2013

(C) The Author(s) 2013. This article is published with open access at Springerlink.com

\begin{abstract}
Plant responses to abiotic stresses are very complex phenomena with individual characteristics for various species. Abiotic stresses (e.g. drought, salinity, flooding, cold, heat, UV radiation, heavy metals, etc.) strongly affect plant growth and development. It is estimated that they are the cause of more than $50 \%$ of crop yield losses. Abiotic stresses are known to activate a multigene response resulting in the changes in various proteins and primary and secondary metabolite accumulation. Therefore, proteomic and metabolomic approaches are becoming very important and powerful tools used in studying plants' reaction to various stimuli. Precise analysis of proteome and metabolome is essential for understanding the fundamentals of stress physiology and biochemistry. In this review, we focus on recent reports
\end{abstract}

Communicated by P. Wojtaszek.

P. Rodziewicz, K. Chmielewska, B. Swarcewicz and A. Wojakowska contributed equally to this work.

P. Rodziewicz · B. Swarcewicz $\cdot$ K. Chmielewska

A. Wojakowska $\cdot$ M. Stobiecki $(\square)$

Institute of Bioorganic Chemistry, Polish Academy of Sciences,

Noskowskiego 12/14, 61-704 Poznan, Poland

e-mail: mackis@ibch.poznan.pl

P. Rodziewicz

e-mail: prod@ibch.poznan.pl

B. Swarcewicz

e-mail: bars@ibch.poznan.pl

K. Chmielewska

e-mail: klaudias@ibch.poznan.pl

A. Wojakowska

e-mail: astasz@ibch.poznan.pl concerned to the influence of abiotic stresses on changes in the level of different protein groups and metabolite classes. Basic information about physicochemical methods applied to qualitative and quantitative analyses of biopolymers and natural products is also briefly presented.

Keywords Abiotic stress - Crop plants - Enzymes · Mass spectrometry $\cdot$ Metabolites · Metabolome ·

Proteins $\cdot$ Proteome

\section{Introduction}

Abiotic stresses are the major factors which negatively influence plant development and productivity. They are the main cause of extensive agricultural production losses worldwide (Barnabas et al. 2008; Athar and Ashraf 2009). Among abiotic stresses, drought, salinity and extreme temperatures are the major environmental constraints that modern agriculture has to cope with. It has been estimated that they may be responsible for over $50 \%$ yield reduction in major crop plants. However, severity of losses depends on the plant development stage at which the stress occurs, its intensity and duration (Bray et al. 2000; Ashraf et al. 2008; Atteya 2003; Monneveux et al. 2006; Lafitte et al. 2007).

According to the United Nations Food and Agriculture Organization (FAO), up to $26 \%$ of arable land is subjected to drought and over $20 \%$ of the irrigated land is salt-affected (Rehman et al. 2005; Pitman and Lauchli 2002). Thus, as the climatic conditions are getting worse, new resistant crop varieties are needed. It is possible to obtain them through the selection of cross-bred lines or by the means of genetic engineering. However, better understanding of the mechanisms involved in plant stress 
responses is necessary to reach that goal. Incorporation of modern knowledge into traditional breeding strategy is necessary for development of new varieties with improved adaptation to non-optimal environmental conditions.

Plant responses towards abiotic stresses have been the subject of various researches since decades. Initially focused on the model plants, now moved to various crop plants like wheat, barley, rice, maize, and other economically important species. The development of the "omics" technologies (e.g. genomics, transcriptomics, proteomics, metabolomics) has revolutionized plant science research and has enabled more holistic study of interactions among biological components using models and/or networks to integrate genes, metabolites, proteins, regulatory elements, fluxes and other, this methodology is defined as systems biology (Yuan et al. 2008). Recent research permitted to explain functions of many key genes, proteins, metabolites and molecular networks involved in plant responses to salinity, drought, heat, cold, heavy metals and other abiotic stresses.

Subsequent development of dense chromosome maps enabled identification of corresponding quantitative trait loci (QTLs), which became a key molecular tool used in plant breeding programs, defined as marker-assisted selection (Tuberosa and Salvi 2004). However, despite newer and more complex results, there are still lots of unknown in molecular processes occurring in plants while coping with a stress.

Proteome and metabolome analyses have become powerful tools to monitor changes in response to various environmental stimuli. The results of such studies give insight into the functioning of plants under specified conditions and are an indispensable part in revealing the molecular mechanisms underlying responses to abiotic stresses (Setia and Setia 2008; Weckwerth and Kahl 2013). The knowledge of the key proteins and metabolites involved in plant growth, development and response to various stress conditions and proper interpretation of the data enables the identification of potential biomarkers linked to enhanced tolerance to adverse environmental factors and is critical for the introduction of desired biological features to crop plant (Salekdeh and Komatsu 2007). Appropriate analytical methods capable of identifying and monitoring changes in protein and metabolite accumulation are crucial. Nowadays mass spectrometry combined with various chromatographic or electrophoretic techniques plays a central role in proteome and metabolome analysis. In this article we have reviewed main protein groups and metabolite classes, which were identified in the recent reports concerning proteomic and metabolomic analyses of plants subjected to various abiotic stresses. Some instrumental methods directed to analysis of biopolymers and natural products in plant material are also presented.

\section{Instrumentation applied in proteomic and metabolomic studies}

Identification of proteins and metabolites is mainly based on application of mass spectrometric techniques hyphenated to chromatographic instrumentation and electrophoretic techniques. Proper choice of ionization method and analyzer type used in mass spectrometer in protein and/or metabolite analysis is crucial. Both "omics" need rather different configuration of mass spectrometric (MS) instrumentation (Glinski and Weckwerth 2006).

During analysis with mass spectrometry ionized molecules are measured. The values of mass to charge ratio $(\mathrm{m} / \mathrm{z}, \mathrm{m}$-mass and $\mathrm{z}$-charge) of created ions are estimated after separation in the MS analyzer with accuracy of one mass unit (atomic mass unit-amu) or to the fourth decimal point, low- and high-resolution mass spectra, respectively. Application of high-resolution mass analyzers permits to conclude about elemental composition of the detected ions presented in mass spectra. This information is important during investigation on structural characterization of studied compounds with MS techniques. First of all, it is possible to estimate molecular mass and elemental composition of the molecules from registered $\mathrm{m} / \mathrm{z}$ values for protonated $[\mathrm{M}+\mathrm{H}]^{+}$or deprotonated molecules $[\mathrm{M}-$ $\mathrm{H}]^{-}$. Fragment or product ions registered in the MS spectra bring additional data about the structure. Unambiguous identification of compounds is in high degree dependent on the mass spectrometric system applied. Various strategies of mass spectrometric identification and quantification of proteins were established in the past two decades. MS instruments equipped with electrospray ionization (ESI) or matrix-assisted laser desorption/ionization (MALDI) source may be used. The MALDI ionization may be coupled to one or two combined time of flight analyzers (TOF or TOF/TOF). The electrospray ionization (ESI) source works well with quadrupole (Q), ion trap (IT), time of flight (TOF) analyzers and combination of them, quadrupole/time of flight (qTOF) for instance. The highest resolution in mass analyzer can be achieved with ion cyclotron resonance with Fourier transformation instruments (FT ICR MS), when ESI is used as ionization method. Tandem mass spectrometric analyses (MS/MS), which enable the fragmentation of proteins or peptides performed by collision induced dissociation (CID), electron transfer dissociation (ETD) or electron capture dissociation (ECD) are widely used.

Identification of proteins may be performed after separation of proteins present in the sample by electrophoretic 
methods on polyacrylamide gels developed in one or two dimensions. Excised gel fragments containing proteins are subjected to enzymatic digestion (proteolysis with trypsin or other proteases). Arisen peptides are then analyzed by mass spectrometry and molecular masses of peptides are recorded as protonated molecules $[\mathrm{M}+\mathrm{H}]^{+}$. In this approach, peptide mass spectra of peptides mixture are recorded and identification of proteins is realized on the basis of consecutive peptide maps created from registered mass spectra after sample proteolysis. The second technology is called shotgun proteomics. This approach relies on direct digestion of proteins present in the extract sample. The obtained peptide mixture is further separated by $1 \mathrm{D}$ or $2 \mathrm{D}$ chromatographic system hyphenated to mass spectrometer. In the first method, proteins are identified after MS analysis on the basis of the registered $[\mathrm{M}+\mathrm{H}]^{+}$ ions originating from the peptides present in the sample after proteolysis (peptides maps). The second method relays on deciphering of amino acid sequence from the registered CID MS/MS spectra of the peptides ions subjected to fragmentation (bottom-up approach). This application allows also proteins quantification (Swanson and Washburn 2005). In the top-down method of protein identification utilization of mass spectrometer instruments with very high resolution is required (above 100,000 at full width at half maximum-FWHM). Orbitrap or ion cyclotron resonance mass spectrometers (FT ICR) enable analysis of intact proteins and their sequencing (Yates et al. 2009).

In the case of metabolomics studies several different MS analyzer configurations with low- and high-resolution combined to gas or liquid chromatographs are used. The choice of the system strongly depends on physicochemical properties of studied compounds. Molecular masses and polarity of the components present in the samples should be taken into account while choosing a proper identification system (Villas-Bôas et al. 2004). It is also very important to design the experiments according to the standards of Metabolomic Standard Initiative (Sumner et al. 2007; Fiehn et al. 2007), which recommends defined procedures for the proper biological material preparation, metabolite extraction procedures and analytical protocols. According to the published rules, suitable number of sample repetitions (biological and technical), plant growth conditions have to be monitored and described, also control of MS parameters during mass spectra registration is required. This information provides conditions for appropriate identification of compounds and further quantitation of metabolites and reliable statistical calculation (Sansone et al. 2007).

Interpretation of big data sets requires appropriate and advanced statistical methods. Preliminary analysis includes usage of mathematical computing for chromatographic peak retention time alignment between individual analyses. After utilization of this procedure various statistical calculations may be performed in order to quantify the amounts of metabolites, which enables determining the changes of a particular compound in defined conditions (van den Berg et al. 2006; Goodacre et al. 2007; Korman et al. 2012; Weckwerth and Kahl 2013).

The number of primary and secondary metabolites may vary from a few thousands to tens of thousands in a single organism and their concentrations differ in several orders of magnitude. On other hand, the dynamic range of mass spectrometers applied as detectors in metabolomic analyses usually does not exceed five orders of magnitude. In these circumstances, detection and identification of all compounds present in a sample originating from single organism is not possible due to the separation power of chromatographic systems and sensitivity range of mass spectrometers. Several strategies for analysis of metabolites have been developed: metabolite profiling, metabolic fingerprinting, metabolite target analysis and metabonomics (Dunn and Ellis 2005).

\section{Proteomics}

Activation of stress-responsive pathways on different molecular levels due to environmental adverse conditions causes significant changes in plant proteome. Proteins fulfill a vast diversity of functions. They act as enzymes, transcriptional factors, interact with other molecules, have protective functions, are involved in energy transfer or radicals scavenging and take part in signaling pathways and others. Specific composition of proteins present in cells in the defined environmental conditions reflects the true biochemical outcome of genetic information and indicates the biochemical pathways that may be involved. It is now accepted that explaining proteome changes is critical for understanding of rules with which cells work and adapt towards various stimuli. Much attention has been paid to proteomic studies on crop plants in recent years. Examples of researches on crop plants include, among others, barley (Ashoub et al. 2013), maize (Pechanova et al. 2013) rice (Lee et al. 2009), wheat (Peng et al. 2009) and soybean (Cheng et al. 2010) subjected to various abiotic stresses. Especially, comparative proteomic studies based on analyzing contrasting plant genotypes in the stressed and non-stressed conditions are very informative and give insights into the plant reactions to environmental stimuli. Depending on the tolerance level of the studied genotype, plants may accumulate or enhance expression of particular proteins, which exhibit the protective functions. Various classes of molecules may be considered, for example heat-shock proteins, 
proteins involved in osmolyte biosynthesis or belonging to ROS-scavenging systems and others.

Correlation of results obtained on the proteome level with other data, such as genetic, transcriptomic, metabolomic and physiological parameters, may contribute to discovery of biomarkers linked to enhanced tolerance to the defined stress. This information may be further incorporated into breeding programs.

\section{Heat shock proteins}

Abiotic stresses cause protein dysfunction, thus maintaining proteins at the proper conformation by preventing them from aggregation and incorrect folding is crucial for plant survival under severe conditions. Heat shock proteins (HSP or chaperones) are a large family of proteins playing roles in keeping cellular homeostasis both under optimal growth conditions and under stress. They are responsible for correct folding, translocation and degradation of proteins. They also prevent proteins from aggregation. The role of HSPs in abiotic stresses has been extensively reviewed (Wang et al. 2004; Timperio et al. 2008; Al-Whaibi 2011). In plants, similarly to prokaryotes and other eukaryotes, five major families of HSPs are recognized. They are classified on the basis of their approximate molecular weight and according to their amino acid sequence homologies and functions: (1) HSP100 family; (2) HSP90 family; (3) HSP70 family; (4) HSP60 family; (5) small HSP family (sHSP; 15-40 kDa) (Kotak et al. 2007; Gupta et al. 2010). The HSP100/Clp takes part in the removal and reactivation of aggregated, misfolded, non-functional polypeptides (Agarwal et al. 2001). Proteins belonging to HSP90 class play a role in protein folding and regulation of signal transduction (Buchner 1999; Pratt and Toft 2003). The HSP70 family prevents newly synthesized proteins from aggregation and helps them to fold correctly. They are also involved in transport and proteolytic degradation of unstable proteins ( $\mathrm{Su}$ and $\mathrm{Li}$ 2008). Proteins of HSP60 family are crucial to achieve native forms by newly synthesized proteins. For example, they assist in the proper folding of RUBISCO (Wang et al. 2004). Among all HSPs/ chaperonins in plants, small HSPs represent the most prevalent and diverse family with respect to their sequence homology, functions and cellular location (Waters et al. 1996). They cannot refold non-native proteins; however, they bind to partially folded or denatured proteins and prevent aggregation or non-functional folding. They are also capable of degrading misfolded proteins (Sun et al. 2002). HSPs are known to be inducible by various abiotic stresses, including drought, salinity, high and low temperatures, light, ozone and metal stress (Wang et al. 2003; Sabehat et al. 1998; Lee et al. 2000). The comparison of global expression of genes coding HSP and their transcriptional factors (Hsf) in response to different abiotic stresses was recently investigated. It was revealed that most Hsfs and HSPs had similar response and regulation patterns under different stresses; however, some of those genes showed a highly specific response to distinct factors $(\mathrm{Hu}$ et al. 2009). In the study, in which proteomic response of rice leaves to high temperatures was examined, 18 out of a total of 48 identified proteins belonged to HSPs. Among them, members of HSP70, HSP100, DnaK-type, molecular chaperone BiP were identified and showed up-regulation. Such a result may reflect a rapid adaptation to changing environmental conditions. Seven induced sHSPs were also found (Lee et al. 2007). In the reports concerning barley (Süle et al. 2004) and wheat (Majoul et al. 2003), the upregulation and induction of HSPs were also observed. Plants that are exposed to low temperatures also synthesize HSPs (Miura and Furumoto 2013). In particular, the upregulation of HSP70, HSP100 and sHSPs is commonly reported (Cui et al. 2005; Hashimoto and Komatsu 2007). The comparative analysis of barley leaves subjected to drought stress revealed the upregulation of HSP100, HSP90 in both sensitive and tolerant genotype. A member of HSP70 was found to be down-regulated only in the sensitive genotype (Ashoub et al. 2013). In the study conducted by Kausar and co-workers, HSP70 was also down-regulated in drought-sensitive barley (Kausar et al. 2013). Three HSP70 proteins were down-regulated during the analysis of sugar beet leaves (Hajheidari et al. 2005). HSP90 and HSP70 were found to be required for stomata closure and modulation of transcriptional responses to abscisic acid (Clèment et al. 2011); thus, they may be crucial for enhanced drought-tolerance. Tobacco plants overexpressing NtHSP70-1 demonstrated higher tolerance to water deficiency (Cho and Hong 2006). In the analysis of the changes in the proteome of grasspea exposed to salinity and drought, HSP 70 was found to be up-regulated in the plants exposed to increased salinity and drought (Chattopadhyay et al. 2011). HSP70 was noted to be up-regulated in both conditions. HSP70 proteins were also evaluated as potential markers of heavy metal, osmotic and heat stress (Ireland 2004).

Late embryogenesis abundant proteins

Late embryogenesis abundant proteins (LEA) were originally discovered more than three decades ago in cotton seed, where they were synthesized and accumulated during late embryo development (Dure et al. 1981). In plants, LEA proteins and their mRNAs accumulate to high concentrations in the embryo tissue during the last stages of seed development (Baker et al. 1988). Dehydrins constitute one of the groups of LEA proteins (Roberts et al. 1993). These proteins play a significant role in plant response and 
adaptation to abiotic stresses. The synthesis of dehydrins may be induced in the vegetative tissue by various stress factors. The role of LEA proteins in abiotic stress tolerance was widely documented and may suggest that in general these proteins are active to adaptation to various abiotic stresses, such as drought, salinity and low-temperature, but their precise function remains still unclear (Bray 1993). It seems that these proteins play a critical role in cellular protection during the osmotic shock. They stabilize the cell and protect the tissue from water loss. In the research conducted by Ford and co-workers, three wheat cultivars with different tolerance level have been evaluated under drought conditions. Dehydrin COR410 was up-regulated in all studied genotypes in comparison with the control plants. However, the most significant change in the expression level of that protein was observed in the intolerant cultivar (Ford et al. 2011). Lopez and co-workers during their research found a correlation between the accumulation of dehydrin in seven winter wheat cultivars during the exposure to water deficit. Three of the tested cultivars showed a significantly enhanced expression of $24 \mathrm{kDa}$ dehydrin in comparison with other genotypes (Lopez et al. 2003). In control plants of other analyzed genotypes, the expression of these proteins was not detected. The enhanced accumulation of dehydrin was related to the acquisition of drought tolerance, which was characterized by a greater growth of shoots in three most tolerant cultivars. Although the role of dehydrin remains unknown, the authors suggest that LEA proteins might be used to improve the adaptation in drought conditions. In another study, seedlings of two barley cultivars with contrasting tolerance [differentiation based on the Relative Water Content (RWC) analysis] to water deficit were subjected to proteomic analysis. Increased accumulation of dehydrin DHN3 and DHN4 was observed in the tolerant variety, but not in the sensitive one. Similar results were obtained with mature plants. The authors also suggest that the correlation between Dhn3 and Dhn4 transcript accumulation and several traits associated with drought tolerance (RWC and drought yield index) can serve as potential markers to determine drought-tolerant genotypes (Park et al. 2006). Transgenic wheat expressing the barley LEA gene HVAl showed increased desiccation tolerance, which was correlated with biomass productivity (Sivamani et al. 2000). Quantitative differences in dehydrin gene expression and dehydrin protein accumulation under extreme temperatures have been studied in wheat. The correlation between an increase of WCS120 LEA protein synthesis and the level of acquired frost tolerance has been shown (Houde et al. 1992). Two barley cultivars with contrasting responses to salinity were evaluated by Wiztel and co-workers. The identified LEA proteins did not show any differences in the expression pattern of tested genotypes between stressed and control plants (Witzel et al.
2009). In another study it was shown that the expression of the durum wheat dehydrin DHN5 in A. thaliana led to an increase in tolerance toward salt and osmotic stress in transgenic plants (Brini et al. 2007). Likewise, increased tolerance to drought and salinity was also observed in tobacco expressing Rab16A LEA gene from salt-tolerant rice (RoyChoudhury et al. 2007). Cheng and coworkers showed that overexpression of the wheat PMA80 dehydrin in rice enhanced its tolerance to drought and salinity (Cheng et al. 2002). It seems that LEA proteins, in particular dehydrins, can be used as molecular markers for stress tolerance. However, the obtained results are not always clear and easy for interpretation and sometime are contradictory.

\section{Osmolyte biosynthetic enzymes}

Compatible solutes like glycine betaine (GB) or proline play an important role in enhancing plant resistance of abiotic stresses, including drought, salinity and temperature stress. Osmolytes exhibit protective functions on enzymes and membrane integrity and take part in regulation of osmotic pressure. During abiotic stresses their synthesis usually increases in plants (Quan et al. 2004a; Chen and Murata 2011). Betaine aldehyde dehydrogenase (BADH) is an enzyme involved in the synthesis of glycine betaine through the conversion of betaine aldehyde. Studies of transgenic plants overexpressing BADH suggest higher accumulation of glycine betaine and were correlated with increased tolerance to abiotic stresses, including water deficit and salinity (Chen and Murata 2011; Turan et al. 2012). Accumulation of betaine glycine in the transgenic line of wheat with overexpressing BADH gene showed an enhanced tolerance to cold (Zhang et al. 2010). The transgenic wheat containing gene encoding BADH cloned from Atriplex hortensis showed increased tolerance to drought and heat stress. It was also found that overproduction of betaine glycine enhances photosynthesis and antioxidant activity in wheat (Wang et al. 2010). Tobacco overexpressing BADH gene was found to be more tolerant to salinity than its wild counterpart. It also showed enhanced $\mathrm{CO}_{2}$ assimilation and increased activity of the enzymes involved in photosynthesis (Yang et al. 2008).

The key enzyme involved in the metabolic pathway of proline is delta-1-pyrroline-5-carboxylate synthetase (P5CS) (Verbruggen and Hermans 2008). Proline is one of the most abundant osmolytes synthesized in response to environmental stresses. Research indicates that high accumulation of proline in plants correlates with an increased tolerance toward water deficit (Nayyar and Walia 2003). A study performed by Zhu and coworkers on transgenic rice overexpressing P5CS showed an enhanced tolerance to osmotic stress caused by salinity and drought. Transgenic 
plants demonstrated an increase of biomass under salt and water stress in comparison with non-transformed plants (Zhu et al. 1998). It was also demonstrated that proline overproduction in transgenic tobacco led to lower reduction of leaf osmotic potentials during drought, when comparing with the wild plants. Reduction of proline synthesis, hypersensitivity to high concentration of salt and accumulation of reactive oxygen species were observed in the research conducted on $A$. thaliana P5CS knockout mutants (Székely et al. 2008). These results suggest that proline accumulation may be involved in the tolerance to osmotic stress, caused by other adverse factors such as drought or salinity.

\section{Photosynthesis and carbon metabolism}

Abiotic stresses disturb cell homeostasis and affect photosynthetic metabolism. The rate of photosynthesis usually decreases during exposure to various stresses in higher plants (Chaves et al. 2009). The main reason is stomata closure, which leads to decrease in internal $\mathrm{CO}_{2}$ concentration (Cornic 2000). However, as the stress progresses, the metabolic impairment of the photosynthetic apparatus starts to be an important issue. Drought, salinity, high/low temperatures, ultraviolet radiation and excessive light generate additional oxidative stress caused by enhanced production of reactive oxygen species, which further damages the photosynthetic machinery (Mittler 2002).

Ribulose-1,5-bisphosphate carboxylase/oxygenase (RUBISCO) is an enzyme involved in the major step in the $\mathrm{CO}_{2}$ incorporation into organic compound and the competing photorespiratory carbon oxidation (Spreitzer and Salvucci 2002). A decrease in RUBISCO activity was identified as one of the non-stomatal reasons for lowering the photosynthesis rate (Flexas et al. 2006). However, the reduction of RUBISCO activity under drought stress is not primarily caused by lower $\mathrm{CO}_{2}$ concentrations, but rather due to the presence of tight-bound inhibitors, for example phosphorylated carbohydrates (Parry et al. 2002). The effect of drought on the activity of RUBISCO may vary from strong to none, depending on the analyzed species, its tolerance to the stress and differences in experimental design (Parry et al. 2002). In the study conducted by Ashoub and coworkers, it was found that RUBISCO was more down-regulated in the drought-sensitive barley genotype than in the tolerant one. Transketolase, an enzyme involved in the Calvin cycle, showed a greater decrease in the accumulation profile in the sensitive cultivar. Glyoxysomal malate dehydrogenase and alanine glyoxylate aminotransferase, which are enzymes involved in photorespiration were increased, especially in the tolerant genotype suggesting a higher rate of photorespiration (Ashoub et al. 2013; Aubry et al. 2011). In another study concerning drought responses in barley, the following proteins were considered: RUBISCO-binding protein, RUBISCO activase and Photosystem I Reaction Centre II. These proteins were decreased in the sensitive genotypes. The carbon-metabolism-related proteins such as malate dehydrogenase and triosephosphate isomerase were upregulated in tolerant species or showed no significant change, while in sensitive one they were down-regulated (Kausar et al. 2013). However, in a study conducted by Wendelboe-Nelson and Morris large subunits of RUBISCO and other photosynthetic enzymes were generally found to be down-regulated in a tolerant variety (Wendelboe-Nelson and Morris 2012). The effect of drought and salinity stress studied on a somatic hybrid of wheat and its parent also revealed degradation of the RUBISCO enzyme. However, greater amounts of the fragmented RUBISCO subunits were observed in parental genotype, it was also in agreement with the measured rate of photosynthesis and chlorophyll activity, which were higher for the hybrid. The capacity to sustain photosynthesis under stress by the somatic hybrids may be the result of effective removal of ROS and more robust homeostasis (Peng et al. 2009). In salt-stressed plants of wheat (Triticum durum L.), small subunits of RUBISCO were found to be down-regulated. Two different fragments of the large RUBISCO subunit were up-regulated, suggesting degradation occurring under that stress condition and decreased synthesis of the enzyme. On the other hand, two molecular chaperones, RUBISCO activase and RUBISCO-binding protein, were up-regulated during stress treatment. It may suggest a role in protecting proteins against the denaturation of RUBISCO under stress conditions. Phosphoglycerate kinase, which catalyzes the first reaction in the reduction phase in the Calvin cycle, was decreased in salt-stressed wheat. It may be connected to a decrease of $\mathrm{CO}_{2}$ fixation caused by the reduction of stomata conductance and degradation of RUBISCO. Other enzymes involved in metabolic pathways such as pentose phosphate pathway (phosphoribulokinase) and glycolysis (fructose 1,6-bisphosphate aldolase) showed a decreased abundance, in comparison with control plants. However, enzymes involved in the regulation of carbon metabolism (phosphopyruvate hydratase, triose phosphate isomerase, glucose-6-phosphate dehydrogenase) were upregulated in salt-treated plants (Caruso et al. 2008). An increased number of RUBISCO proteolytic fragments was also reported in metal-stressed rice (Hajduch et al. 2001). In the seedlings subjected to the cold, RUBISCO large subunits and RUBISCO-binding protein were also downregulated, which may suggest the chloroplast damage.

Enzymes related to energy production were shown to be activated under low temperatures (Hashimoto and Komatsu 2007). During a study conducted on spring wheat exposed to prolonged cold stress, a massive down-regulation of 
photosynthetic proteins was observed. Identified enzymes from the Calvin and Krebs cycles were also down-regulated. Oxygen-evolving enhancer protein, which stabilizes the manganese cluster, the primary site of water splitting in Photosystem II and ferredoxin NADPH oxidoreductase, which participates in energy and electron transfer, were both down-regulated, suggesting disturbances in electron flow through the photosynthetic machinery. Fragmentation of RUBISCO was also evidenced, with a greater degradation of small subunits. It was suggested that RUBISCO proteolysis is caused by an increased ROS concentration and sugar accumulation during cold exposure. However, RUBISCO activase, which removes tight-bound inhibitors, was up-regulated, which may be related to the reactivation of RUBISCO to fix remaining $\mathrm{CO}_{2}$ (Rinalducci et al. 2011). Analysis of rice leaves subjected to high temperatures $\left(42{ }^{\circ} \mathrm{C}\right)$ for $24 \mathrm{~h}$ also revealed down-regulation of photosynthesis-related proteins, including RUBISCO (Lee et al. 2007). Similar findings were reported by Gammulla and coworkers. They subjected rice seedlings to various high and low temperatures for $72 \mathrm{~h}$. Most of the proteins involved in the light-harvesting complex were responsive to either high- or low-temperature stress or both. The identified RUBISCO large subunit decreased its abundance at different temperatures: $44 / 36,12 / 5$ and $20 / 12{ }^{\circ} \mathrm{C}$ (day/ night), with the most significant decrease shown at $20 / 12{ }^{\circ} \mathrm{C}$ (day/night) (Gammulla et al. 2011). In the study concerned with cold acclimation of Festuca pratensis, half of all selected proteins that were differentially accumulated before and during cold acclimation in plants of different levels of frost tolerance were directly involved in the process of photosynthesis (oxygen-evolving protein, cytochrome $b_{6} / f$ and Rieske $\mathrm{Fe}-\mathrm{S}$ protein). One of the differences observed between the sensitive and tolerant genotypes was the down-regulation of RUBISCO in the low frost tolerant species. These results may suggest an important role of the chloroplast machinery in plant acclimation to cold (Kosmala et al. 2009).

\section{Enzymatic reactive oxygen species scavengers}

Partially oxidized oxygen particles, known as the reactive oxygen species (ROS), unlike atmospheric oxygen, have the capability of oxidizing various molecules and cell structures. Under normal environmental conditions, ROS are naturally present in plants; however, plants developed various antioxidant systems to balance their production and quantity (Gill and Tuteja 2010a). Main forms of ROS that arise in plants are the superoxide radical $\left(\mathrm{O}_{2}^{-}\right)$, hydrogen peroxide $\left(\mathrm{H}_{2} \mathrm{O}_{2}\right)$, singlet oxygen $\left({ }^{1} \mathrm{O}_{2}\right)$ and hydroxyl radical $\left(\mathrm{HO}_{2}^{-}\right)$(Mittler 2002). They are by-products of biological processes that take place in organelles with a high metabolic activity like chloroplasts (during photosynthesis)
(Pfannschmidt 2003), mitochondria (electron transport chain) (Rasmusson et al. 2004) or peroxisomes (photorespiration, $\beta$-oxidation) (del Río et al. 2002). Although the ROS are considered to be very toxic for the plant, especially at high concentrations, they also play a role in signaling and are involved in the activation of defense responses and in acclimation to changing environmental conditions (Dat et al. 2000). Various stresses, both abiotic and biotic, cause excessive production of ROS (Polle 2001). In the case of abiotic stresses, diminished concentrations of internal $\mathrm{CO}_{2}$ due to stomata closing leads to the leakage of electrons to $\mathrm{O}_{2}$ and is one of the main reasons for the excessive ROS production. If the generation of ROS exceeds the plant scavenging capacity, it will cause disturbances in cell homeostasis and, as a further consequence, may activate processes leading to cell death (Dat et al. 2000). Plants developed various antioxidant mechanisms, both enzymatic and non-enzymatic, which very often form a common metabolic pathway. The ascorbateglutathione cycle is one of the major ROS scavenging pathways. The enzymatic components of this cycle are ascorbate peroxidase (APX), monodehydroascorbate reductase (MDHAR), dehydroascorbate reductase (DHAR), glutathione reductase, utilize ascorbic acid and glutathione to scavenge $\mathrm{H}_{2} \mathrm{O}_{2}$ (Jimenez et al. 1997). Other significant ROS removal enzymes are superoxide dismutase (SOD), which is one of the most effective antioxidants, which catalyzes the removal of $\mathrm{O}_{2}^{--}$by its dismutation to $\mathrm{H}_{2} \mathrm{O}_{2}$ and $\mathrm{O}_{2}$. SODs are found in various locations within the cell. They are classified by the metal cofactor they require: manganese (Mn-SOD), iron (Fe-SOD) and copper/ zinc (Cu/Zn-SOD) (Mittler 2002). Catalases (CAT) found in the peroxisomes are very efficient enzymes capable of dismutating $\mathrm{H}_{2} \mathrm{O}_{2}$ to $\mathrm{H}_{2} \mathrm{O}$ and $\mathrm{O}_{2}$ (Polidoros and Scandalio 1999). Other enzymes involved in antioxidant defense include glutathione-S-transferases (GST) (Dixon et al. 2011) and various peroxiredoxins (PRX) (Dietz 2003), of which some are implicated in the water/water cycle (Rizhsky et al. 2003). The regulation of the expression of the ROS-scavenging enzymes differs between the plant species, depending on the tolerance level to the stress and its intensity. The increased activities of APX and SOD were found in all three analyzed varieties of beans in response to drought, but the CAT activity was up-regulated only in two of them. Moreover, in the variety with the highest APX and CAT activity, the lowest $\mathrm{H}_{2} \mathrm{O}_{2}$ production and lipid peroxidation were observed (Zlatev et al. 2006). Shotgun proteomic analysis of wheat cultivars subjected to drought revealed that $\mathrm{Cu} / \mathrm{Zn}$ SOD and CAT were highly up-regulated in both tolerant and sensitive genotypes (Ford et al. 2011). An increased activity of APX at mild drought was also reported in rice seedlings. However, the intensification of the stress diminished its activity (Sharma and 
Dubey 2005). In the comparative study of dehydrationsensitive and -tolerant cultivars of chickpea, SOD, APX and GST were found to be induced only in the resistant genotype. Another enzyme, glyoxalase, involved in the detoxification of $R$-oxoaldehydes, was also up-regulated in the tolerant variety. The lack of induction of major ROS catabolic enzymes may lead to hypersensitivity of plants during dehydration-induced oxidative stress (Subba et al. 2013). The up-regulation of glyoxylate was also observed in rice root tissue in response to cold treatment (Lee et al. 2009). In another study concerning the analysis of coldinduced changes of proteins in the roots of rice seedlings, APX was found to be up-regulated and also its phosphorylation pattern was changed (Chen et al. 2012). According to a recent review on maize proteome, APX and SOD belong to proteins whose accumulation is the most influenced by various abiotic stresses, which shows the importance of ROS catabolism during plant acclimation (Pechanova et al. 2013). The effect of aluminum and cadmium on antioxidant enzyme activities in two barley cultivars revealed that the activity of SOD was higher in the resistant genotype (Guo et al. 2004). Among the cadmium-induced defense-related proteins between high- and low-cadmium-accumulating cultivars of soybean, the enhanced expressions of antioxidant enzymes, APX, CAT and $\mathrm{Cu} / \mathrm{Zn} \mathrm{SOD}$, were evident in both genotypes (Hossain et al. 2012). Analysis of the changes in the proteome of the roots of pea in response to salinity also revealed an increased accumulation of SOD, but no other antioxidant enzymes were identified (Kav et al. 2004). The study of changes in the root proteome of barley genotypes with a contrasting response towards salinity revealed that the MDAR, APX and CAT showed a higher constitutional expression level in the sensitive genotype and two of them (MDAR, APX) were found to be more down-regulated during the salinity treatment in the tolerant genotype. However, two identified proteins involved in the glutathione-based detoxification of the reactive oxygen species (ROS) were more abundant in the tolerant cultivar. The higher constitutive expression of these proteins in the more tolerant genotype could represent a pre-formed tolerance mechanism (Witzel et al. 2009).

\section{Other proteins}

Another group of proteins responding to abiotic stresses are proteins involved in the secondary metabolism. Phenylalanine ammonia lyase (PAL) is the first enzyme of the phenylpropanoid pathway, which catalyzes the conversion of phenylalanine to cinnamic acid. The phenylpropanoid pathway is crucial for the biosynthesis of lignins, phenolic acids and flavonoids, which play important roles in plant defense mechanisms (Vogt 2010).
Lignins, which are synthesized from phenylpropanoid compounds play a crucial role in conducting water in plant stem. Increased resistance to drought was observed in $A$. thaliana pal1 pal2 double mutants, which might have been the effect of the reduced lignin synthesis as the mutants contained only $30 \%$ of the lignin level typical for the wild type. The reduced lignin contents in the double mutants might cause a reduced efficiency of water transport in the vascular tissue (Huang et al. 2010). The effects of drought stress on the activity of PAL in maize revealed an increased activity of this enzyme in leaves, while in the roots it remained constant. The antioxidant activity in leaves was also enhanced. It may suggest that PAL is a responsive antioxidative enzyme in the leaves, but not in roots (Ashraf 2011). In a study performed by Hura and co-workers, drought-tolerant and -sensitive wheat genotypes were selected, based on their field performance and biochemical parameters. The activity of PAL and phenolic compounds' synthesis level was correlated with crop yield and according to these values, the level of wheat resistance to water deficit was described (Hura et al. 2007).

The protein synthesis elongation factor (EF-Tu protein) plays a role in the elongation phase of protein biosynthesis. This protein has been studied in several plants in response to abiotic stress, such as extreme temperatures, salinity and drought. EF-Tu acts as a molecular chaperone and protects other proteins from thermal aggregation and degradation (Rao et al. 2004). The first report regarding stress-induced expression and accumulation of the elongation factor (EF) showed such effect in maize. It was indicated that there was a correlation between the increased accumulation of $\mathrm{EF}$ in plastids and the heat tolerance of maize lines (Ristic et al. 1991). Similar results were obtained as an effect of combined heat and drought stress applied to this plant (Ristic et al. 1999). The analysis of the proteome and transcriptome of maize indicated that the expression of EF$\mathrm{Tu}$ factor was regulated differentially in heat-tolerant and sensitive cultivars. A significant increase in the accumulation of both the EF-Tu transcript and EF-Tu protein was observed in tolerant genotypes of maize. The authors suggested that regulation of the expression of EF-Tu may be different in heat-tolerant and sensitive genotypes (Momcilovic and Ristic 2007).

Transcription factors (TF) are the specific group of proteins that play a regulatory role in gene control. TF factors have the ability to control the expression of target genes through binding to the specific sequence in these genes. Large plant TF families play significant roles in response to abiotic stress (Nakashima et al. 2009). In a study of the influence of long-term drought on wheat there was demonstrated enhanced expression of MYB transcript factor in a tolerant genotype in comparison with the susceptible genotype. Similar results have been obtained 
during studies on salt stress, which may suggest that the MYB transcription factor plays an important regulatory function in adaptation to abiotic stress in wheat (Rahaie et al. 2013). In another study, it was demonstrated that overexpression of the transcription factor GmbZIP1 did not result in growth inhibition of wheat seedlings subjected to drought stress, suggesting enhanced tolerance to water deficit (Gao et al. 2011).

\section{Metabolomics}

Metabolomics is currently an important tool involved in the selection process of plants resistant to changing climatic conditions. The most important abiotic stress factors, such as drought, salinity, soil flooding and extreme temperatures, cause significant changes in the composition of the plant metabolome (Obata and Fernie 2012; Ruan et al. 2013) The knowledge about the role played by lowmolecular-weight primary and secondary metabolites in the stress tolerance process is essential for crop species improvement. However, the function of secondary metabolites in the abiotic stress tolerance of plants is relatively least understood nowadays.

\section{Role of primary metabolites in response to abiotic stress}

Plants developed various adaptive strategies to withstand abiotic stresses, including alterations of metabolism in different directions, to ensure their survival under adverse environmental conditions. One of the widely described plant responses to water deficit is osmotic adjustment, which requires accumulation of compatible solutes, such as amino acids, carbohydrates, polyols, tertiary sulfonium and quaternary ammonium compounds (especially glycine betaine). These molecules play an important role in maintaining cell turgor, as well as stabilizing proteins and cell membranes. Other hypothesis indicates their contribution in re-establishing the redox balance by scavenging reactive oxygen species, which could negatively affect cellular structures and metabolism. In cold stress, the content of cryoprotective molecules, such as soluble sugars, sugar alcohols and nitrogen-containing compounds is increased. This helps plant to cope with low temperatures by preventing ice adhesion to plasma membrane, which can be followed by cell disruption (Rontein et al. 2002; Bartels and Sunkar 2005; Valliyodan and Nguyen 2006; Munns and Tester 2008; Janská et al. 2010).

\section{Amino acids}

It has been documented that many amino acids accumulate in plants exposed to various abiotic stresses. Proline is one of the most widely distributed osmolyte, the level of which is elevated in different environmental stresses including drought, salinity and cold stress (Verbruggen and Hermans 2008; Szabados and Savoure 2010). This stress-responsive amino acid is predominantly synthesized from glutamate through pyrroline-5-carboxylate (P5C) by two reductions catalyzed by pyrroline-5-carboxylate synthetase (P5CS) and pyrroline-5-carboxylate reductases (P5CR) (Hu et al. 1992). The important role of proline in osmotic stress was confirmed in transgenic plants, e.g. by P5CS overexpression in tobacco, which led to an increased proline content and a smaller decrease in osmotic potentials in the leaf of transgenic plants, compared with control plants after drought treatment (Kavi Kishor et al. 1995). Therefore, the increased levels of proline in plants in response to abiotic stresses were for many years regarded to be the stresstolerance trait. Recently, the relationship between the accumulation of osmolytes and stress tolerance has been discussed because of its questionable relevance to crop yield (Serraj and Sinclair 2002). The increased content of some amino acids, including proline, tryptophan, phenylalanine and histidine was reported in a research on maize hybrids subjected to drought stress (Witt et al. 2012). Interestingly, very few metabolites were linked with drought tolerance or drought susceptibility of the studied hybrids. On the other hand, studies on drought response at the metabolomic level in Andean potatoes revealed that plants with a phenotype indicating higher stress susceptibility had increased proline content as compared with genotypes, which were more drought-resistant (VasquezRobinet et al. 2008). In studies on barley subjected to salinity stress, it was found that the cultivar with a sensitive phenotype had an elevated level of some amino acids, including proline and GABA. It may suggest a higher susceptibility of these plants to this kind of stress. The authors proposed that this accumulation might be related to leaf necrosis and slower growth of the more sensitive genotype (Widodo et al. 2009). Furthermore, data obtained in research on Arabidopsis show that proline can be a toxic compound and harmful for plant growth during heat stress (Lv et al. 2011).

\section{Polyamines}

Polyamines are low-molecular-weight nitrogen compounds with a positive charge at the cellular $\mathrm{pH}$, which enables them to interact with negatively charged molecules like nucleic acids, proteins and phospholipids. The most common polyamines are triamine spermidine ( $\mathrm{Spd})$, tetraamine spermine (Spm) and their diamine precursor putrescine (Put). Due to their cationic nature, these commonly occurring compounds have been frequently related with environmental stresses, including drought, salinity and 
chilling stress, as well as UV-B and heavy metals (KaurSawhney et al. 2003; Groppa and Benavides 2008; Hussain et al. 2011). Polyamines have been ascribed to be involved in the stabilization of membranes protecting them from denaturation under stress condition (Slocum et al. 1984), scavenging free radicals (Drolet et al. 1986), modulating nucleic acid structures and also enzyme activities or function (Galston and Sawhney 1990). Moreover, it was suggested that they might act as osmolytes because their function is similar to those of proline and other compatible solutes (Hussain et al. 2011). Additionally, several authors indicated that polyamines may act as a cellular signal during stress response (Alcázar et al. 2010a, b; Gill and Tuteja 2010b). Polyamine levels change under environmental stress conditions. In some cases, their content increases as it was presented in the experiments on wheat, in which elevated content of Put and Spd was observed after cold treatment, as well as higher levels for Spm after polyethylene glycol-induced osmotic stress were registered (Kovács et al. 2010). In other cases, decreased levels of polyamines were observed as a consequence of the stress. Under long-term salt stress, a significant reduction of free Put and Spm was noted in in vitro grown apple shoots (Liu et al. 2008).

\section{Carbohydrates}

It was widely reported that abiotic stresses lead to accumulation of nonstructural carbohydrates like sucrose, hexoses and polyhydric alcohols among many plant species. Especially, there is a strong correlation between the carbohydrate accumulation and tolerance to osmotic stresses, such as water deficit or salinity stress (Bartels and Sunkar 2005). Soluble carbohydrates play an important role in plant metabolism as a source of carbon and energy within a cell. Their level might be affected by different stresses, as the carbohydrate content is related to photosynthesis. Contents of some carbohydrates including sucrose, raffinose, glucose, fructose and maltose increased, whereas the myoinositol level decreased in water-stressed barley roots (Sicher et al. 2012). Soluble sugars function as osmoprotectants during water deficit, reducing the detrimental effects of osmotic stress, helping in maintaining turgor, stabilizing cell membranes and protecting plants from degradation (Basu et al. 2007). The increase in sugar content is mostly the effect of starch hydrolysis, which requires enzymes with a hydrolytic activity (Kaplan and Guy 2004). Furthermore, soluble sugars like sucrose, raffinose, stachyose, trehalose and sugar alcohols, like sorbitol, ribitol and inositol, act as cryoprotectants during cold stress, protecting cell membranes against ice adhesion (Janská et al. 2010). In addition, carbohydrates may act as signaling molecules (Hanson and Smeekens 2009) and play a role in adaptive mechanisms to stress (Ramel et al. 2009). Moreover, trehalose, a rare, non-reducing disaccharide, the presence of which was multiple times related to stress tolerance in bacteria (Purvis et al. 2005) and fungi (Cao et al. 2008), also accumulates in plants and seems to play a protective role during abiotic stress; however, its specific function is not well understood. In general, trehalose is not accumulated at high levels and, except some resurrection plants, it is barely detectable in crop plants (Fernandez et al. 2010). Nevertheless, its metabolism in the response of grapevine to chilling stress was studied recently (Fernandez et al. 2012). Interestingly, not only trehalose, but also trehalose-6-phosphate accumulated in grapevine tissue as the effect of stress and their increase might be the reason for the resistance to this abiotic stress. The authors highlighted the possible function of trehalose-6-phosphate as an active compound in the stress response and suggested its link with the metabolism of sucrose. In addition, Garg and coworkers demonstrated that transgenic rice with the overexpression of trehalose biosynthetic genes was characterized by the enhanced tolerance to salinity and drought stress (Garg et al. 2002). Transgenic lines shown in this study had improved physiological parameters, such as sustained plant growth, less photo-oxidative damage, favorable mineral balance as well as a higher accumulation of trehalose, compared with nontransgenic controls. These researchers suggested that trehalose might be involved in sugar sensing and carbohydrate metabolism rather than being a compatible solute.

\section{Glycine betaine}

Another extensively studied osmoprotectant is glycine betaine ( $N, N, N$-trimethylglycine). Glycine betaine is a quaternary ammonium compound, which is involved in maintaining water balance, stabilizing macromolecules, protecting photosynthesis and detoxificating reactive oxygen radicals (Chen and Murata 2011). Many studies have reported its important role in enhancement of plant tolerance against abiotic stresses. However, not every crop species accumulates significant amounts of glycine betaine during stress. To this group belong wheat, maize and barley. Additionally, some of the crops do not accumulate glycine betaine at all, like rice (Giri 2011). Therefore, attempts to achieve transgenic plants with enhanced tolerance through glycine betaine biosynthesis have been made. One of the studies concerned transgenic maize accumulating higher levels of glycine betaine than the wild types. As a result of such a transformation, transgenic maize better sustained chilling stress, as compared with non-transformants (Quan et al. 2004b). Furthermore, other transgenic crop plants were achieved through genetic engineering and tested against environmental stresses, 
including tobacco with increased tolerance to salinity and low temperature stress (Holmström et al. 2000). Moreover, Brassica juncea with enhanced tolerance to salinity demonstrated a higher capacity to germinate under stress conditions and higher growth, as compared with the wild type (Prasad et al. 2000). Additionally, tomato plants were more tolerant to chilling stress and, what was important, the fruit yield was 10-30\% higher as compared with that of the wild type (Park et al. 2004). Furthermore, faster recovery after elimination of salt stress was observed in transgenic rice than in the wild type (Sakamoto et al. 1998). However, concentrations of glycine betaine synthesized in any transgenic plant were insufficient to overcome osmotic stress, to which plants were subjected. Perhaps other protective mechanisms of glycine betaine, which may lead to the tolerance effect, such as protection against oxidative stress, must be taken into consideration ( $\mathrm{Su}$ et al. 2006).

Role of secondary metabolites in response to abiotic stresses

Secondary metabolites create a diverse group of compounds, which are regarded to play an important role in many biochemical and biophysical processes occurring in plant cells and tissues. These natural products are synthesized by the specified plant species and their concentration level is precisely regulated by the developmental stage, environmental conditions and adaptation processes. Secondary metabolites are involved in defense reaction during pathogen infections; they play a role as attractants or repellents against herbivores and insects as well as provide protection against the harmful effect of UV radiation. They are also involved in protective functions in response to biotic and abiotic stress conditions (Ahuja et al. 2010; Fernie and Schauer 2009; Kliebenstein 2004).

\section{Phenolic compounds}

Phenolic compounds constitute a large and diverse group of plant secondary metabolites that include phenylpropanoids and their polymers, namely lignins and tannins, as well as flavonoids, isoflavonoids, anthocyanins and coumarins. These low-molecular-weight natural products are synthesized in plants through the phenylpropanoid pathway, in which phenylalanine is the key substrate (Boudet 2007). Accumulation of phenolic compounds is regulated by environmental stresses, such as UV irradiation, light, wounding, pathogen attack, herbicide treatment, nutrient deficiencies. Drought, high salinity, temperature and soil flooding are environmental factors that significantly affect the development of plants and the productivity of crops (Ramakrishna and Ravishankar 2011).
The content of the phenylpropanoids, which are intermediates in lignin biosynthesis, alters under drought stress in different tissues. Concentration of $p$-coumaric acid and caffeic acid increased, while the ferulic acid level was decreased in maize xylem sap under water scarcity. It was suggested, that these precursors of monolignols may be involved in lignification and cell wall stiffening processes (Alvarez et al. 2008). Alterations in the metabolism and accumulation of wall-linked phenolic compounds in maize root elongation zone were connected with water deficit in another work. Spatially localized changes in wall phenolics were shown to be involved in the progressive inhibition of wall extensibility and root growth, which might facilitate root acclimation to drying environments (Fan et al. 2006). The polyphenol content in cotton (Gossypium hirsutum) leaves was increased in drought-stressed plants. The level of these natural products was significantly higher in the tolerant genotype than in the sensitive one. These results suggest that polyphenols are involved in the maintenance of the osmotic potential in cells and in scavenging free radicals under water-stress condition (Parida et al. 2007). Other researchers concluded that the diverse polyphenolic profiles were correlated with changes in gene expression profiles of potato plants during drought stress; however, the changes were highly cultivar-specific. This knowledge could be useful in the development of improved potato varieties (André et al. 2009). The content of phenolics is also altered under increased salinity conditions. Navarro et al. (2006) observed greater contents of total phenolic compounds in red pepper fruits under salinity stress. The production of antioxidative polyphenol compounds in response to salinity in halophytes was also observed (Ksouri et al. 2007). Cold stress induces the production of phenolic compounds and their incorporation into the cell wall either as suberin or lignin. Lignins constitute an important stress defense mechanism. The biosynthesis of lignins depends on the stress intensity and the plant development stage at which it occurred (Moura et al. 2010). Lignification and suberin deposition may play a significant role in the improved resistance to cold stress (Janská et al. 2010; Pérez-Ilzarbe et al. 1997).

Biosynthesis of flavonoids, isoflavonoids and anthocyanins is stimulated by various environmental stresses. Flavonoids have protective functions in plants exposed to water deficit because of their antioxidant properties. The oxidation products of flavan-3-ols increased in droughtstressed tea leaves (Hernández et al. 2006). Water stress, both waterlogging and drought, increased the level of flavonoids: quercetin and rutin in the medicinal herb $\mathrm{Hy}$ pericum brasiliense, while temperature treatments cause a varied response (de Abreu and Mazzafera 2005). Fortyseven flavonoids were identified in eaves of two citrus species and most of their contents changed in response to 
flooding. The most differentiating compounds were quercetin, kaempferol, eriodictyol and apigenin. Higher relative reduction in flavonoids was observed in the sensitive genotype, which may indicate that the stability of flavonoid content is important in maintaining higher antioxidant activity under water stress (Djoukeng et al. 2008). Wu and co-workers showed that it was possible to use isoflavonoids to discriminate between closely related soybean genotypes. Genistin was identified as the key secondary metabolite correlated with salt tolerance and could be useful as a biomarker candidate for salt tolerance traits and, therefore, may be used in crop breeding (Wu et al. 2008). In another work, the level of flavonoids in two species of hawthorn varied depending on the type of environmental stress factors. Water deficit or cold stress treatment, or a combination of the two, caused an increase in the level of flavonoid accumulation, while flooding and herbivores in some cases decreased the content of these natural products (Kirakosyan et al. 2004).

Anthocyanins were reported to increase their content in plant tissue in response to salt, drought and cold stress (Christie et al. 1994; Chalker-Scott 1999; Parida and Das 2005). However, high salinity induced a decrease in the anthocyanin level in the salt-sensitive species of potatoes, (Daneshmand et al. 2010). Plant tissues with a higher content of anthocyanins usually have a higher resistance to drought. The purple cultivar of pepper is more tolerant to water stress than the green cultivar (Bahler et al. 1991). A low-temperature treatment induced an increased level of anthocyanin in the strawberry cell culture (Zhang et al. 1997).

\section{Terpenoids}

Terpenoids constitute a broad class of lipophilic secondary metabolites synthesized in plants from isoprene units, which may be further assembled and modified in many different ways (Langenheim 1994). These natural products exhibit a positive effect against both biotic and abiotic stress factors. Terpenoids show an antioxidant and antibiotic activity, take part in defense responses against herbivores, play an important role in the stabilization of the lipid membrane and improve environmental stress tolerance (Cheng et al. 2007). Drought causes changes in the level of chlorophyll and carotenoids. The decreased content of these terpenoid compounds was reported in cotton under drought stress (Parida et al. 2007; Massacci et al. 2008). Overexpression of key enzymes involved in carotenogenesis was observed in transgenic tobacco under drought and salt stress (Cidade et al. 2012). Moreover, the carotenoid content of citrus juice was dependent on the temperature conditions. The tropical citrus fruits had a lower carotenoid level than fruits developed in Mediterranean climatic zone
(Dhuique-Mayer et al. 2009). In the study on Brassica juncea, researchers demonstrated that the increased content of tocopherol plays an important role in the alleviation of stress induced by salt, heavy metal and osmotic potential (Yusuf et al. 2010). Furthermore, saponins were identified as one of the key secondary metabolites correlated with salt tolerance in soybean (Wu et al. 2008).

\section{Nitrogen-containing secondary metabolites}

Glucosinolates are plant secondary metabolites that contain sulfur and nitrogen and are derived from glucose and amino acids. These natural products take part in response to different biotic and abiotic stress factors. In A. thaliana, drought stress and water-logging led to increased aliphatic glucosinolate and flavonoid levels (Mewis et al. 2012). Similarly, the increased glucosinolate content was observed in rape leaf tissue (Brassica napus) subjected to water deficit occurring during vegetative growth (Jensen et al. 1996).

Another group of nitrogen-containing secondary metabolites are alkaloids. Most of these compounds have bitter taste and play an important role during the plant defense reaction against herbivores and pathogens attack. Moreover, the production of alkaloids is induced under abiotic stress. Poppy (Papaver somniferum) produced a higher level of the alkaloids under drought conditions (Szabó et al. 2003). The alkaloid content was also affected by drought treatment applied on different growth stages of the three narrow-leafed lupin (Lupinus angustifolius) genotypes (Christiansen et al. 1997).

\section{Summary}

Observation of the influence of environmental stimuli on plants and their responses registered on protein and metabolite level provides lots of valuable information about mechanisms underlying plant acclimation; however, the current knowledge about the role of proteins and metabolites involved in this process is still incomplete. Moreover, due to differences in experimental design, tested species and applied technology the results are not always uniform and sometimes may be contradictory which additionally hampers the explanation of the role that particular protein or metabolite and biochemical pathway play in plant reaction to adverse condition. Various abiotic stresses have different impact on proteome and metabolome changes; however, a part of the plant response is similar and thus some general conclusions may be drawn. In general proteins related to photosynthesis, rate of which usually decreases under abiotic stresses like drought, salinity or high temperatures are down-regulated. Reduced 
carbon fixation further decreases carbon metabolism; thus lower level of enzymes involved in primary carbon metabolism is very often observed. Generally in tolerant species the reduction of these enzymes is decreased, when compared with susceptible genotypes. During stress plants activate various defense mechanisms. Secondary oxidative stress induces extensive ROS production. Enzymatic and non-enzymatic ROS scavengers are reported to be upregulated, especially in tolerant genotypes. Primary metabolites involved in osmotic adjustment, especially in conditions of limited water availability, are generally found to have elevated concentration level. However, in some sensitive species this parameter was higher than in tolerant species. Various classes of heat shock proteins are very often reported to be up-regulated during abiotic stresses. Particularly those related to high or low temperatures, which may cause increase in level of misfolded and/or aggregated proteins. Secondary metabolites which are involved in defense mechanisms are also found to be upregulated in resistant species. It seems that withstanding adverse abiotic factors largely depends on the ability to keep appropriate level of primary metabolic processes and activate opposite defense mechanisms.

The explanation of the role of particular proteins and metabolites during plant acclimation may also contribute to the discovery of molecular markers of enhanced tolerance to determined stress (Ireland et al. 2004). Such markers may be used in engineering new varieties with superior resistance (Gill and Tuteja 2010a) or may be helpful in distinguishing the tolerance level among tested genotypes in conventional breeding programs. However, most of the research focused on plant responses to abiotic stresses take into account only one adverse condition. Many results covering the area of only one applied stress has been discussed in this article. Plants are exposed to variety of adverse factors occurring simultaneously on the field. Therefore, laboratory-gained results may not reflect all processes occurring in the natural environment. For example, in many areas of the world, drought is accompanied by high temperatures and increased salt concentration due to lower water content. At present, plant responses to a multiple stresses are still poorly understood. Recent studies revealed that the responses of plants to a combination of stresses is unique and may be different than the response to each stress applied separately (Hu et al. 2009; Rizhsky et al. 2002, 2004). This may explain why some of the transgenic plants with the enhanced tolerance towards one factor do not perform well on the field (Thomas et al. 2004). Simultaneous occurrence of two or more stresses may have a negative or positive interaction on the activating plant defense mechanisms; therefore, it should be considered as a new condition that requires individual responses (Mittler 2006). Varieties or lines tested in comparative studies are usually selected in such a way that they represent tolerant and sensitive genotypes. Although such approach is correct and gives clues about differences in the response of such plants, the tolerance level is very often determined only according to physiological traits. Usually the following parameters are measured: relative water content (RWC), water loss rate (WLR) (WendelboeNelson and Morris 2012), value of fast chlorophyll fluorescence analysis (Ashoub et al. 2013), photosynthesis rate, shoot and root length and fresh weight (Kausar et al. 2013). Obviously, such analyses provide information about the differences in resistance to abiotic factors between the genotypes, but if the studied plant is a crop species, its crop yield should also be measured and taken into consideration while determining the tolerance level (Verslues et al. 2006; Dolferus et al. 2011). Another problem is, that even among the genotypes considered to be tolerant response to the adverse factor often varies and does not always provide uniform results, which additionally hampers the discovery of the potential biomarkers. Analyzing mapping populations would be a good suggestion in such a case and it may give insight how a particular protein/metabolite changes among all tested genotypes. This may help to determine their impact on the tolerance level. Despite the progress in "omic" technology identification of biomarkers for breeding new resistant crop varieties has not been fully realized, further development of bioinformatics and better integration of data from different molecular levels is required to reveal full picture of adaptive mechanisms, which will lead to novel biomarkers of tolerance to abiotic stresses (Abreu et al. 2013; Vanderschuren et al. 2013). At present, there are not many databases which contain information gathered from different molecular levels (Baker 2008). The bases should also allow comprehensive correlation between molecular data and plant physiological traits. Accomplishment of these goals will permit better understanding of molecular and physiological mechanisms utilized by plants during adverse growth conditions and define the biomarkers of resistance against stresses.

Special interest should also be directed to applications of proper and robust physicochemical methods during proteome and metabolome analyses, appropriate strategies of biological material preparation are also important (Taylor et al. 2007; Fiehn et al. 2007) In particular the number of sample repetitions have a great influence on the results during proteome and/or metabolome analyses (Moco et al. 2007; Mann et al. 2013).

Author contribution Paweł Rodziewicz, Barbara Swarcewicz, Klaudia Chmielewska, Anna Wojakowska, Maciej Stobiecki drafted entire manuscript. MS edited the manuscript. All the authors read corrected and approved the manuscript in its final form. 
Acknowledgments This work was supported by the European Regional Development Fund through the Innovative Economy Program for Poland 2007-2013, Project WND-POIG.01.03.01-00-101/08 POLAPGEN-BD: "Biotechnological tools for breeding cereals with increased resistance to drought". The project is realized by POLAPGEN Consortium coordinated by Institute of Plant Genetics, Polish Academy of Sciences in Poznan. Further information about the project can be found at http://www.polapgen.pl.

Open Access This article is distributed under the terms of the Creative Commons Attribution License which permits any use, distribution, and reproduction in any medium, provided the original author(s) and the source are credited.

\section{References}

Abreu IA, Farinha AP, Negrão S, Gonçalves N, Fonseca C, Rodrigues M, Batista R, Saibo NJM, Oliviera MM (2013) Coping with abiotic stress: proteome changes for crop improvement. J Prot. doi:10.1016/j.jprot.2013.07.014

Agarwal M, Katiyar-Agarwal S, Sahi C, Gallie DR, Grover A (2001) Arabidopsis thaliana Hsp100 proteins: kith and kin. Cell Stress Chaperon 6:219-224

Ahuja I, de Vos RCH, Bones AM, Hall RD (2010) Plant molecular stress responses face climate change. Trends Plant Sci 15: 664-674

Alcázar R, Altabella T, Marco F, Bortolotti C, Reymond M, Knocz C, Carrasco P, Tiburcio AF (2010a) Polyamines: molecules with regulatory functions in plant abiotic stress. Planta 231: $1237-1249$

Alcázar R, Planas J, Saxena T, Zarza X, Bortolotti C, Cuevas J, Bitrián M, Tiburcio AF, Altabella T (2010b) Putrescine accumulation confers drought tolerance in transgenic Arabidopsis plants over-expressing the homologous Arginine decarboxylase 2 gene. Plant Physiol Biochem 48:547-552

Alvarez S, Marsh EL, Schroeder SG, Schachtman DP (2008) Metabolomic and proteomic changes in the xylem sap of maize under drought. Plant Cell Environ 31:325-340

Al-Whaibi MH (2011) Plant heat-shock proteins: a mini review. J King Saud Univ Sci 23:139-150

André CM, Schafleitner R, Legay S, Lefèvre I, Aliaga CA, Nomberto G, Hoffmann L, Hausman JF, Larondelle Y, Evers D (2009) Gene expression changes related to the production of phenolic compounds in potato tubers grown under drought stress. Phytochemistry 70:1107-1116

Ashoub A, Beckhaus T, Berberich T, Karas M, Brüggemann W (2013) Comparative analysis of barley leaf proteome as affected by drought stress. Planta 237:771-781

Ashraf G (2011) Effects of drought on the activity of phenylalanine ammonia lyase in the leaves and roots of maize inbreds. Aust $\mathrm{J}$ Basic Appl Sci 5:952-956

Ashraf M, Athar HR, Harris PJC, Kwon TR (2008) Some prospective strategies for improving crop salt tolerance. Adv Agron 97:45-110

Athar HR, Ashraf M (2009) Strategies for crop improvement against salinity and drought stress: an overview. In: Ashraf M, Ozturk M, Athar HR (eds) Salinity and water stress: improving crop efficiency, vol 44, 1st edn. Springer, New York, pp 1-16

Atteya AM (2003) Alteration of water relations and yield of corn genotypes in response to drought stress. Bulg J Plant Physiol 29:63-76

Aubry S, Brown NJ, Hibberd JM (2011) The role of proteins in $\mathrm{C}_{3}$ plants prior to their recruitment into the $\mathrm{C}_{4}$ pathway. $\mathrm{J}$ Exp Bot 62:3049-3059
Bahler BD, Steffen KL, Orzolek MD (1991) Morphological and biochemical comparison of a purple-leafed and a green-leafed pepper cultivar. Hortic Sci 26:736

Baker M (2008) Metabolomics: from small molecules to big ideas. Nat Methods 8:117-121

Baker J, Steele C, Dure L (1988) Sequence and characterization of 6 Lea proteins and their genes from cotton. Plant Mol Biol 11:277-291

Barnabas B, Jagner K, Feher A (2008) The effect of drought and heat stress on reproductive processes in cereals. Plant Cell Environ 31:11-38

Bartels D, Sunkar R (2005) Drought and salt tolerance in plants. Crit Rev Plant Sci 24:23-58

Basu PS, Ali M, Chaturvedi SK (2007) Osmotic adjustment increases water uptake, remobilization of assimilates and maintains photosynthesis in chickpea under drought. Indian J Exp Biol 45:261-267

Boudet A (2007) Evolution and current status of research in phenolic compounds. Phytochemistry 68:2722-2735

Bray EA (1993) Molecular responses to water deficit. Plant Physiol 103:1035-1040

Bray EA, Bailey-Serres J, Weretilnyk E (2000) Responses to abiotic stress. In: Buchanan BB, Gruissen W, Jones RL (eds) Biochemistry and molecular biology of plants, 1 st edn. Wiley, Rockville, pp 1158-1249

Brini F, Hanin M, Lumbreras V, Amara I, Khoudi H, Hassairi A, Pagès M, Masmoudi K (2007) Overexpression of wheat dehydrin DHN5 enhances tolerance to salt and osmotic stress in Arabidopsis thaliana. Plant Cell Rep 26:2017-2026

Buchner J (1999) Hsp90 \& Co.-a holding for folding. Trends Biochem Sci 24:136-141

Cao Y, Wang Y, Dai B, Wang B, Zhang H, Zhu Z, Xu Y, Cao Y, Jiang Y, Zhang G (2008) Trehalose is an important mediator of Caplp oxidative stress response in Candida albicans. Biol Pharm Bull 31:421-425

Caruso G, Cavaliere C, Guarino C, Gubbiotti R, Foglia P, Laganà A (2008) Identification of changes in Triticum durum L. leaf proteome in response to salt stress by two-dimensional electrophoresis and MALDI-TOF mass spectrometry. Anal Bioanal Chem 391:381-390

Chalker-Scott L (1999) Environmental significance of anthocyanins in plant stress responses. Photochem Photobiol 70:1-9

Chattopadhyay A, Subba P, Pandey A, Bhushan D, Kumar R, Datta A, Chakraborty S, Chakraborty N (2011) Analysis of the grasspea proteome and identification of stress-responsive proteins upon exposure to high salinity, low temperature, and abscisic acid treatment. Phytochemistry 72:1293-1307

Chaves MM, Flexas J, Pinheiro C (2009) Photosynthesis under drought and salt stress: regulation mechanisms from whole plant to cell. Ann Bot 103:551-560

Chen TH, Murata N (2011) Glycinebetaine protects plants against abiotic stress: mechanisms and biotechnological applications. Plant Cell Environ 34:1-20

Chen J, Tian L, Xu H, Tian D, Luo Y, Ren C, Yang L, Shi J (2012) Cold-induced changes of protein and phosphoprotein expression patterns from rice roots as revealed by multiplex proteomic analysis. Plant Omics J 5:194-199

Cheng Z, Targolli J, Huang X, Wu R (2002) Wheat LEA genes, PMA80 and PMA1959, enhance dehydration tolerance of transgenic rice (Oryza sativa L.). Mol Breed 10:71-82

Cheng AX, Lou YG, Mao YB, Lu S, Wang LJ, Chen XY (2007) Plant terpenoids: biosynthesis and ecological functions. J Integr Plant Biol 49:179-186

Cheng L, Gao X, Li S, Shi M, Javeed H, Jing X, Yang G, He G (2010) Proteomic analysis of soybean [Glycine $\max$ (L.) Meer.] seeds during imbibition at chilling temperature. Mol Breed 26:1-17 
Cho EK, Hong CB (2006) Over-expression of tobacco NtHSP70-1 contributes to drought-stress tolerance in plants. Plant Cell Rep 25:349-358

Christiansen JL, Jornsgard B, Buskov S, Olsen CE (1997) Effect of drought stress on content and composition of seed alkaloids in narrow-leafed lupin, Lupinus angustifolius L. Eur J Agron 7:307-314

Christie PJ, Alfenito MR, Walbot V (1994) Impact of low-temperature stress on general phenylpropanoid and anthocyanin pathways: enhancement of transcript abundance and anthocyanin pigmentation in maize seedlings. Planta 194:541-549

Cidade LC, de Oliveira TM, Mendes AFS, Macedo AF, Floh EIS, Gesteira AS, Soares-Filho WS, Costa MGC (2012) Ectopic expression of a fruit phytoene synthase from Citrus paradisi Macf. promotes abiotic stress tolerance in transgenic tobacco. Mol Biol Rep 39:10201-10209

Clèment M, Leonhardt N, Droillard MJ, Reiter I, Montillet JL, Genty B, Laurière C, Nussaume L, Noël LD (2011) The cytosolic/ nuclear HSC70 and HSP90 molecular chaperones are important for stomatal closure and modulate abscisic acid-dependent physiological responses in Arabidopsis. Plant Physiol 156:1481-1492

Cornic G (2000) Drought stress inhibits photosynthesis by decreasing stomatal aperture - not by affecting ATP synthesis. Trends Plant Sci 5:187-188

Cui S, Huang F, Wang J, Ma X, Cheng Y, Liu J (2005) A proteomic analysis of cold stress responses in rice seedlings. Proteomics 5:3162-3172

Daneshmand F, Arvin MJ, Kalantari KM (2010) Physiological responses to $\mathrm{NaCl}$ stress in three wild species of potato in vitro. Acta Physiol Plant 32:91-101

Dat J, Vandenabeele S, Vranová E, Van Montagu M, Inzé D, Van Breusegem F (2000) Dual action of the active oxygen species during plant stress responses. Cell Mol Life Sci 57:779-795

de Abreu IN, Mazzafera P (2005) Effect of water and temperature stress on the content of active constituents of Hypericum brasiliense Choisy. Plant Physiol Biochem 43:241-248

del Río LA, Corpas FJ, Sandalio LM, Palma JM, Gómez M, Barroso JB (2002) Reactive oxygen species, antioxidant systems and nitric oxide in peroxisomes. J Exp Bot 53:1255-1272

Dhuique-Mayer C, Fanciullino AL, Dubois C, Ollitrault P (2009) Effect of genotype and environment on citrus juice carotenoid content. J Agric Food Chem 57:9160-9168

Dietz KJ (2003) Plant peroxiredoxins. Annu Rev Plant Biol 54:93-107

Dixon DP, Steel PG, Edwards R (2011) Roles for glutathione transferases in antioxidant recycling. Plant Signal Behav 6:1223-1227

Djoukeng JD, Arbona V, Argamasilla R, Gomez-Cadenas A (2008) Flavonoid profiling in leaves of citrus genotypes under different environmental situations. J Agric Food Chem 56:11087-11097

Dolferus R, Ji X, Richards RA (2011) Abiotic stress and control of grain number in cereals. Plant Sci 181:331-341

Drolet G, Dumbroff EB, Legge RL, Thompson JE (1986) Radical scavenging properties of polyamines. Phytochemistry 25:367-371

Dunn WB, Ellis DI (2005) Metabolomics: current analytical platforms and methodologies. Trends Anal Chem 24:285-294

Dure L, Greenway SC, Galau GA (1981) Developmental biochemistry of cotton seed embryogenesis and germination: changing messenger ribonucleic acid populations as shown by in vitro and in vivo protein synthesis. Biochemistry 20:4162-4168

Fan L, Linker R, Gepstein S, Tanimoto E, Yamamoto R, Neumann PM (2006) Progressive inhibition by water deficit of cell wall extensibility and growth along the elongation zone of maize roots is related to increased lignin metabolism and progressive stelar accumulation of wall phenolics. Plant Physiol 140:603-612

Fernandez O, Béthencourt L, Quero A, Sangwan RS, Clément C (2010) Trehalose and plant stress responses: friend or foe? Trends Plant Sci 15:409-417

Fernandez O, Vandesteene L, Feil R, Baillieul F, Lunn JE, Clément C (2012) Trehalose metabolism is activated upon chilling in grapevine and might participate in Burkholderia phytofirmans induced chilling tolerance. Planta 236:355-369

Fernie AR, Schauer N (2009) Metabolomics-assisted breeding: a viable option for crop improvement? Trends Genet 25:39-48

Fiehn O, Robertson D, Griffin J, van der Werf M, Nikolau B, Morrison N, Sumner LW, Goodacre R, Hardy NW, Taylor C, Fostel J, Kristal B, Kaddurah-Daouk R, Mendes P, van Ommen B, Lindon JC, Sansone SA (2007) The metabolomics standards initiative. Metabolomics 3:155-178

Flexas J, Ribas-Carbó M, Bota J, Galmés J, Henkle M, MartínezCañellas S, Medrano H (2006) Decreased Rubisco activity during water stress is not induced by decreased relative content but related conditions of low stomatal conductance and chloroplast $\mathrm{CO}_{2}$ concentration. New Phytol 172:73-82

Ford KL, Cassin A, Bacic A (2011) Quantitative proteomic analysis of wheat cultivars with differing drought stress tolerance. Front Plant Sci 2:44

Galston AW, Sawhney RK (1990) Polyamines in plant physiology. Plant Physiol 94:406-410

Gammulla CG, Pascovici D, Atwell BJ, Haynes PA (2011) Differential proteomic response of rice (Oryza sativa) leaves exposed to high- and low-temperature stress. Proteomics 11:2839-2850

Gao SQ, Chen M, Xu ZS, Zhao CP, Li L, Xu HJ, Tang YM, Zhao X, Ma YZ (2011) The soybean GmbZIP1 transcription factor enhances multiple abiotic stress tolerances in transgenic plants. Plant Mol Biol 75:537-553

Garg AK, Kim JK, Owens TG, Ranwala AP, Choi YD, Kochian LV, Wu RJ (2002) Trehalose accumulation in rice plants confers high tolerance levels to different abiotic stresses. PNAS 99: $15898-15903$

Gill SS, Tuteja N (2010a) Reactive oxygen species and antioxidant machinery in abiotic stress tolerance in crop plants. Plant Physiol Biochem 48:909-930

Gill SS, Tuteja N (2010b) Polyamines and abiotic stress tolerance in plants. Plant Signal Behav 51:26-33

Giri J (2011) Glycinebetaine and abiotic stress tolerance in plants. Plant Signal Behav 6:1746-1751

Glinski M, Weckwerth W (2006) The role of mass spectrometry in plant systems biology. Mass Spectrom Rev 25:173-214

Goodacre R, Broadhurst D, Smilde AK, Kristal BS, Baker JD, Beger R, Bessant C, Connor S, Capuani G, Craig A, Ebbels T, Kell DB, Manetti C, Newton J, Paternostro G, Somorjai R, Sjöström M, Trygg J, Wulfert F (2007) Proposed minimum reporting standards for data analysis in metabolomics. Metabolomics 3:231-241

Groppa MD, Benavides MP (2008) Polyamines and abiotic stress: recent advances. Amino Acids 34:35-45

Guo T, Zhang G, Zhou M, Wu F, Chen J (2004) Effects of aluminum and cadmium toxicity on growth and antioxidant enzyme activities of two barley genotypes with different $\mathrm{Al}$ resistance. Plant Soil 258:241-248

Gupta SC, Sharma A, Mishra M, Mishra RK, Chowdhuri DK (2010) Heat shock proteins in toxicology: how close and how far? Life Sci 86:377-384

Hajduch M, Rakwal R, Agrawal GK, Yonekura M, Pretova A (2001) High-resolution two-dimensional electrophoresis separation of proteins from metal-stressed rice (Oryza sativa L.) leaves: 
drastic reductions/fragmentation of ribulose-1,5-bisphosphate carboxylase/oxygenase and induction of stress-related proteins. Electrophoresis 22:2824-2831

Hajheidari M, Abdollahian-Noghabi H, Askari H, Heidari M, Sadeghian SY, Ober ES, Salekdeh GH (2005) Proteome analysis of sugar beet leaves under drought stress. Proteomics 5:950-960

Hanson J, Smeekens S (2009) Sugar perception and signaling-an update. Curr Opin Plant Biol 12:562-567

Hashimoto M, Komatsu S (2007) Proteomic analysis of rice seedlings during cold stress. Proteomics 7:1293-1302

Hernández I, Alegre L, Munné-Bosch S (2006) Enhanced oxidation of flavan-3-ols and proanthocyanidin accumulation in waterstressed tea plants. Phytochemistry 67:1120-1126

Holmström KO, Somersalo S, Mandal A, Palva TE, Wellin B (2000) Improved tolerance to salinity and low temperature in transgenic tobacco producing glycine betaine. J Exp Bot 51:177-185

Hossain Z, Hajika M, Komatsu S (2012) Comparative proteome analysis of high and low cadmium accumulating soybeans under cadmium stress. Amino Acids 43:2393-2416

Houde M, Dhindsa RS, Sarhan F (1992) A molecular marker to select for freezing tolerance in Gramineae. Mol Gen Genet 234:43-48

Hu CA, Delauney AJ, Verma DPS (1992) A bifunctional enzyme ( $\Delta^{1}$ pyrroline-5-carboxylate synthetase) catalyses the first two steps in proline biosynthesis in plants. PNAS 89:9354-9358

Hu W, Hu G, Han B (2009) Genome-wide survey and expression profiling of heat shock proteins and heat shock factors revealed overlapped and stress specific response under abiotic stresses in rice. Plant Sci 176:583-590

Huang J, Gu M, Lai Z, Fan B, Shi K, Zhou Y, Yu J, Chen Z (2010) Functional analysis of the Arabidopsis PAL gene family in plant growth, development, and response to environmental stress. Plant Physiol 153:1526-1538

Hura T, Grzesiak S, Hura K, Thhiemt E, Tokarz K, Wedzony M (2007) Physiological and biochemical tools useful in droughttolerance detection in genotypes of winter triticale: accumulation of ferulic acid correlates with drought tolerance. Ann Bot 100:767-775

Hussain SS, Ali M, Ahmad M, Siddique KHM (2011) Polyamines: natural and engineered abiotic and biotic stress tolerance in plants. Biotechnol Adv 29:300-311

Ireland HE, Harding SJ, Bonwick GA, Jones M, Smith CJ, Williams JH (2004) Evaluation of heat shock protein 70 as a biomarker of environmental stress in Fucus serratus and Lemna minor. Biomarkers 9:139-155

Janská A, Marsík P, Zelenková S, Ovesná J (2010) Cold stress and acclimation-what is important for metabolic adjustment? Plant Biol 12:395-405

Jensen CR, Mogensen VO, Mortensen G, Fieldsend JK, Milford GFJ, Andersen MN, Thage JH (1996) Seed glucosinolate, oil and protein contents of field-grown rape (Brassica napus L.) affected by soil drying and evaporative demand. Field Crops Res 47:93-105

Jimenez A, Hernandez JA, del Rio LA, Sevilla F (1997) Evidence for the presence of the ascorbate-glutathione cycle in mitochondria and peroxisomes of pea leaves. Plant Physiol 114:275-284

Kaplan F, Guy CL (2004) $\beta$-Amylase induction and the protective role of maltose during temperature shock. Plant Physiol 135:1674-1684

Kaur-Sawhney R, Tiburcio AF, Altabella T, Galston AW (2003) Polyamines in plants: an overview. J Cell Mol Biol 2:1-12

Kausar R, Arshad M, Shahzad A, Komatsu S (2013) Proteomics analysis of sensitive and tolerant barley genotypes under drought stress. Amino Acids 44:345-359
Kav NNV, Srivastana S, Goonewardene L, Blade SF (2004) Proteome-level changes in the roots of Pisum sativum in response to salinity. Ann Appl Biol 145:217-230

Kavi Kishor PB, Hong Z, Miao GC, Hu CAA, Verma DPS (1995) Overexpression of 1-pyrroline-5-carboxylate synthetase increases proline production and confers osmotolerance in transgenic plants. Plant Physiol 108:1387-1394

Kirakosyan A, Kaufman P, Warber S, Zick S, Aaronson K, Bolling S, Chul Chang S (2004) Applied environmental stresses to enhance the levels of polyphenolics in leaves of hawthorn plants. Physiol Plant 121:182-186

Kliebenstein DJ (2004) Secondary metabolites and plant/environment interactions: a view through Arabidopsis thaliana tinged glasses. Plant Cell Environ 27:675-684

Korman A, Oh A, Raskind A, Banks D (2012) Statistical methods in metabolomics. Methods Mol Biol 856:381-413

Kosmala A, Bocian A, Rapacz M, Jurczyk B, Zwierzykowski Z (2009) Identification of leaf proteins differentially accumulated during cold acclimation between Festuca pratensis plants with distinct levels of frost tolerance. J Exp Bot 60:3595-3609

Kotak S, Larkindale J, Lee U, von Koskull-Döring P, Vierling E, Scharf KD (2007) Complexity of the heat stress response in plants. Curr Opin Plant Biol 10:310-316

Kovács Z, Simon-Sarkadi L, Szűcs A, Kocsy G (2010) Differential effects of cold, osmotic stress and abscisic acid on polyamine accumulation in wheat. Amino Acids 38:623-631

Ksouri R, Megdiche W, Debez A, Falleh H, Grignon C, Abdelly C (2007) Salinity effects on polyphenol content and antioxidant activities in leaves of the halophyte Cakile maritima. Plant Physiol Biochem 45:244-249

Lafitte HR, Yongsheng G, Yan S, Li ZK (2007) Whole plant responses, key processes, and adaptation to drought stress: the case of rice. J Exp Bot 58:169-175

Langenheim JH (1994) Higher plant terpenoids: a phytocentric overview of their ecological roles. J Chem Ecol 20:1223-1280

Lee BH, Won SH, Lee HS, Miyao M, Chung WI, Kim IJ, Jo J (2000) Expression of the chloroplast-localized small heat shock protein by oxidative stress in rice. Gene 245:283-290

Lee DG, Ahsan N, Lee SH, Kang KY, Bahk JD, Lee IJ, Lee BH (2007) A proteomic approach in analyzing heat-responsive proteins in rice leaves. Proteomics 7:3369-3383

Lee DG, Ahsan N, Lee SH, Lee JJ, Bahk JD, Kang KY, Lee BH (2009) Chilling stress-induced proteomic changes in rice roots. J Plant Physiol 166:1-11

Liu JH, Inoue H, Moriguchi T (2008) Salt stress-mediated changes in free polyamine titers and expression of genes responsible for polyamine biosynthesis of apple in vitro shoots. Environ Exp Bot 62:28-35

Lopez CG, Banowetz GM, Peterson CJ, Kronstad WE (2003) Dehydrin expression and drought tolerance in seven wheat cultivars. Crop Sci 43:577-582

Lv WT, Lin B, Zhang M, Hua XJ (2011) Proline accumulation is inhibitory to Arabidopsis seedlings during heat stress. Plant Physiol 156:1921-1933

Majoul T, Bancel E, Triboï E, Ben Hamida J, Branlard G (2003) Proteomic analysis of the effect of heat stress on hexaploid wheat grain: characterization of heat-responsive proteins from total endosperm. Proteomics 3:175-183

Mann M, Kulak NA, Nagaraj N, Cox J (2013) The coming age of complete, accurate, and ubiquitous proteomes. Mol Cell 49:583-590

Massacci A, Nabiev SM, Pietrosanti L, Nematov SK, Chernikova TN, Thor K, Leipner J (2008) Response of the photosynthetic apparatus of cotton (Gossypium hirsutum) to the onset of drought 
stress under field conditions studied by gas-exchange analysis and chlorophyll fluorescence imaging. Plant Physiol Biochem 46:189-195

Mewis I, Khan MAM, Glawischnig E, Schreiner M, Ulrichs C (2012) Water stress and aphid feeding differentially influence metabolite composition in Arabidopsis thaliana L. PLoS One 7:1-15

Mittler R (2002) Oxidative stress, antioxidants and stress tolerance. Trends Plant Sci 7:405-410

Mittler R (2006) Abiotic stress, the field environment and stress combination. Trends Plant Sci 11:15-19

Miura K, Furumoto T (2013) Cold signaling and cold response in plants. Int J Mol Sci 14:5312-5337

Moco S, Bino RJ, De Vos RCH, Vervoort J (2007) Metabolomics technologies and metabolite identification. Trends Anal Chem $26: 855-866$

Momcilovic I, Ristic Z (2007) Expression of chloroplast protein synthesis elongation factor, EF-Tu, in two lines of maize with contrasting tolerance to heat stress during early stages of plant development. J Plant Physiol 164:90-99

Monneveux P, Sánchez C, Beck D, Edmeades GO (2006) Drought tolerance improvement in tropical maize source populations: evidence of progress. Crop Sci 46:180-191

Moura JCMS, Bonine CAV, de Oliveira Fernandes Viana J, Dornelas MC, Mazzafera P (2010) Abiotic and biotic stresses and changes in the lignin content and composition in plants. J Integr Plant Biol 52:360-376

Munns R, Tester M (2008) Mechanisms of salinity tolerance. Annu Rev Plant Biol 59:651-681

Nakashima K, Ito Y, Yamaguchi-Shinozaki K (2009) Transcriptional regulatory networks in response to abiotic stresses in Arabidopsis and grasses. Plant Physiol 149:88-95

Navarro JM, Flores P, Garrido C, Martinez V (2006) Changes in the contents of antioxidant compounds in pepper fruits at ripening stages, as affected by salinity. Food Chem 96:66-73

Nayyar H, Walia DP (2003) Water stress induced proline accumulation in contrasting wheat genotypes as affected by calcium and abscisic acid. Biol Plant 46:275-279

Obata T, Fernie AR (2012) The use of metabolomics to dissect plant responses to abiotic stresses. Cell Mol Life Sci 69:3225-3243

Parida AK, Das AB (2005) Salt tolerance and salinity effects on plants: a review. Ecotoxicol Environ Saf 60:324-349

Parida AK, Dagaonkar VS, Phalak MS, Umalkar GV, Aurangabadkar LP (2007) Alterations in photosynthetic pigments, protein and osmotic components in cotton genotypes subjected to short-term drought stress followed by recovery. Plant Biotechnol Rep $1: 37-48$

Park EJ, Jeknic Z, Sakamoto A, DeNoma J, Yuwansiri R, Murata N, Chen THH (2004) Genetic engineering of glycinebetaine synthesis in tomato protects seeds, plants and flowers from chilling damage. Plant J 40:474-487

Park SY, Noh KJ, Yoo JH, Yu JW, Lee BW, Kim JG, Seo HS, Paek NC (2006) Rapid upregulation of Dehyrin3 and Dehydrin4 in response to dehydration is a characteristic of drought-tolerant genotypes in barley. J Plant Biol 49:455-462

Parry MAJ, Andralojc PJ, Khan S, Lea PJ, Keys AJ (2002) Rubisco activity: effects of drought stress. Ann Bot 89:833-839

Pechanova O, Takáč T, Šamaj J, Pechan T (2013) Maize proteomics: an insight into the biology of an important cereal crop. Proteomics 13:637-662

Peng Z, Wang M, Li F, Lv H, Li C, Xia G (2009) A proteomic study of the response to salinity and drought stress in an introgression strain of bread wheat. Mol Cell Proteomics 8:2676-2686

Pérez-Ilzarbe J, Hernández T, Estrella I, Vendrell M (1997) Cold storage of apples (cv. Granny Smith) and changes in phenolic compounds. Z. Lebensm Unters Forsch A 20:452-455
Pfannschmidt T (2003) Chloroplast redox signals: how photosynthesis controls its own genes. Trends Plant Sci 1:33-41

Pitman MG, Lauchli A (2002) Global impact of salinity and agricultural ecosystems. In: Lauchli A, Luttge U (eds) Salinity: environmental, plants, molecules. Springer, Dotrecht, pp 3-20

Polidoros AN, Scandalio JG (1999) Role of hydrogen peroxide and different classes of antioxidants in the regulation of catalase and glutathione $S$-transferase gene expression in maize (Zea mays L.). Physiol Plant 106:112-120

Polle A (2001) Dissecting the superoxide dismutase-ascorbate peroxidase-glutathione pathway in chloroplasts by metabolic modeling. Computer simulations as a step towards flux analysis. Plant Physiol 126:445-462

Prasad KVSK, Sharmila P, Kumar PA, Pardha Saradhi P (2000) Transformation of Brassica juncea (L.) Czern with bacterial codA gene enhances its tolerance to salt stress. Mol Breed 6:489-499

Pratt WB, Toft DO (2003) Regulation of signaling protein function and trafficking by the hsp90/hsp70-based chaperone machinery. Exp Biol Med 228:111-133

Purvis JE, Yomano LP, Ingram LO (2005) Enhanced trehalose production improves growth of Escherichia coli under osmotic stress. Appl Environ 71:3761-3769

Quan R, Shang M, Zhang H, Zhao Y, Zhang J (2004a) Engineering of enhanced glycine betaine synthesis improves drought tolerance in maize. Plant Biotechnol J 2:477-486

Quan R, Shang M, Zhang H, Zhao Y, Zhang J (2004b) Improved chilling tolerance by transformation with betA gene for the enhancement of glycinebetaine synthesis in maize. Plant Sci 166:141-149

Rahaie M, Xue GP, Schenk PM (2013) The role of transcription factors in wheat under different abiotic stress. In: Vahdati K, Leslie C (eds) Abiotic stress-plant responses and applications in agriculture. Intech. doi:10.5772/54795

Ramakrishna A, Ravishankar GA (2011) Influence of abiotic stress signals on secondary metabolites in plants. Plant Signal Behav 6:1720-1731

Ramel F, Sulmon C, Gouesbet G, Couée I (2009) Natural variation reveals relationships between pre-stress carbohydrate nutritional status and subsequent responses to xenobiotic and oxidative stress in Arabidopsis thaliana. Ann Bot 104:1323-1337

Rao D, Momcilovic I, Kobayashi S, Callergari E (2004) Chaperone activity of recombinant maize chloroplast protein synthesis elongation factor, EF-Tu. Eur J Biochem 271:3684-3692

Rasmusson AG, Soole KL, Elthon TE (2004) Alternative NAD(P)H Dehydrogenases of plant mitochondria. Annu Rev Plant Biol 55:23-39

Rehman S, Harris PJC, Ashraf M (2005) Stress environments and their impact on crop production. In: Ashraf M, Harris PJC (eds) Abiotic stresses: plant resistance through breeding and molecular approaches, 1st edn. Haworth Press, New York, pp 3-18

Rinalducci S, Egidi MG, Karimzadeh G, Jazii FR, Zolla L (2011) Proteomic analysis of a spring wheat cultivar in response to prolonged cold stress. Electrophoresis 32:1807-1818

Ristic Z, Gifford DJ, Cass DD (1991) Heat shock proteins in two lines of Zea mays L. that differ in drought and heat resistance. Plant Physiol 97:1430-1434

Ristic Z, Yang G, Bhadula SK (1999) Two-dimensional gel analysis of $45 \mathrm{ku}$ heat shock proteins from a drought and heat resistant maize line. J Plant Physiol 154:264-268

Rizhsky L, Liang H, Mittler R (2002) The combined effect of drought stress and heat shock on gene expression in tobacco. Plant Physiol 130:1143-1151

Rizhsky L, Liang H, Mittler R (2003) The water-water cycle is essential for chloroplast protection in the absence of stress. J Biol Chem 278:38921-38925 
Rizhsky L, Liang H, Shuman J, Shulaev V, Davletova S, Mittler R (2004) When defense pathways collide: the response of Arabidopsis to a combination of drought and heat stress. Plant Physiol 134:1683-1696

Roberts JK, DeSimone N, Lingle WL, Dure L (1993) Cellular concentrations and uniformity of cell-type accumulation of two LEA proteins in cotton embryos. Plant Cell 5:769-780

Rontein D, Basset G, Hanson AD (2002) Metabolic engineering of osmoprotectant accumulation in plants. Metab Eng 4:49-56

RoyChoudhury A, Roy C, Sengupta DN (2007) Transgenic tobacco plants overexpressing the heterologous lea gene Rab16A from rice during high salt and water deficit display enhanced tolerance to salinity stress. Plant Cell Rep 26:1839-1859

Ruan CJ, Rumpunen K, Nybom H (2013) Advances in improvement of quality and resistance in a multipurpose crop: sea buckthorn. Crit Rev Biotechnol 33:126-144

Sabehat A, Lurie S, Weiss D (1998) Expression of small heatshock proteins at low temperatures. A possible role in protecting against chilling injuries. Plant Physiol 117:651-658

Sakamoto A, Murata A, Murata N (1998) Metabolic engineering of rice leading to biosynthesis of glycinebetaine and tolerance to salt and cold. Plant Mol Biol 38:1011-1019

Salekdeh GH, Komatsu S (2007) Crop proteomics: aim at sustainable agriculture of tomorrow. Proteomics 7:2976-2996

Sansone SA, Fan T, Goodacre R, Griffin JL, Hardy NW, KaddurahDaouk R, Kristal BS, Lindon J, Mendes P, Morrison N, Nikolau B, Robertson D, Sumner LW, Taylor C, van der Werf M, van Ommen B, Fiehn O (2007) The metabolomics standards initiative. Nat Biotechnol 25:846-848

Serraj R, Sinclair TR (2002) Osmolyte accumulation: can it really help increase crop yield under drought conditions? Plant Cell Environ 25:333-341

Setia RC, Setia N (2008) The "omics" technologies and crop improvement. In: Setia RC, Harash N, Setia N (eds) Crop improvement: strategies and applications, 1st edn. International Publishing House Pvt. Ltd., New Delhi, pp 1-17

Sharma P, Dubey RS (2005) Modulation of nitrate reductase activity in rice seedlings under aluminium toxicity and water stress: role of osmolytes as enzyme protectant. J Plant Physiol 162:854-864

Sicher RC, Timlin D, Bailey B (2012) Responses of growth and primary metabolism of water-stressed barley roots to rehydration. J Plant Physiol 169:686-695

Sivamani E, Bahieldin A, Wraith JM, Al-Niemi T, Dyer WE, Ho TD, $\mathrm{Qu}$ R (2000) Improved biomass productivity and water use efficiency under water deficit conditions in transgenic wheat constitutively expressing the barley $H V A 1$ gene. Plant Sci 155:1-9

Slocum RD, Kaur-Sawhney R, Galston AW (1984) The physiology and biochemistry of polyamines in plants. Arch Biochem Biophys 235:283-303

Spreitzer RJ, Salvucci ME (2002) RUBISCO: structure, regulatory interactions and possibilities for a better enzyme. Annu Rev Plant Biol 53:449-475

Su PH, Li HM (2008) Arabidopsis stromal 70-kD heat shock proteins are essential for plant development and important for thermotolerance of germinating seeds. Plant Physiol 146:1231-1241

Su J, Hirji R, Zhang L, He C, Selvaraj G, Wu R (2006) Evaluation of the stress-inducible production of choline oxidase in transgenic rice as a strategy for producing the stress-protectant glycine betaine. J Exp Bot 57:1129-1135

Subba P, Kumar R, Gayali S, Shekhar S, Parveen S, Pandey A, Datta A, Chakraborty S, Chakraborty N (2013) Characterization of the nuclear proteome of a dehydration-sensitive cultivar of chickpea and comparative proteomic analysis with a tolerant cultivar. Proteomics. doi:10.1002/pmic.201200380
Süle A, Vanrobaeys F, Hajós G, Van Beeumen J, Devreese B (2004) Proteomic analysis of small heat shock protein isoforms in barley shoots. Phytochemistry 65:1853-1863

Sumner LW, Amberg A, Barett D, Bealle MH, Beger R, Daykin CA, Fan TW-M, Fiehn O, Goodacre R, Griffin JL, Hankemeier T, Hardy N, Harnly J, Higashi R, Kopka J, Lane AN, Lindon JC, Mariott P, Nicholls AW, Reilly MD, Thaden JJ, Viant MR (2007) Proposed minimum reporting standards for chemical analysis. Metabolomics 3:211-221

Sun W, Van Motangu M, Verbruggen N (2002) Small heat shock proteins and stress tolerance in plants. Biochim Biophys Acta 19:1-9

Swanson SK, Washburn MP (2005) The continuing evolution of shotgun proteomics. Drug Discov Today Targets 10:719-725

Szabados L, Savoure A (2010) Proline: a multifunctional amino acid. Trends Plant Sci 15:89-97

Szabó B, Tyihak E, Szabó LG, Botz L (2003) Mycotoxin and drought stress induced change of alkaloid content of Papaver somniferum plantlets. Acta Bot Hung 45:409-417

Székely G, Ábrahám E, Cséplo A, Rigó G, Zsigmond L, Csiszár J, Ayaydin F, Strizhov N, Jásik J, Schmelzer E, Koncz C, Szabados L (2008) Duplicated P5CS genes of Arabidopsis play distinct roles in stress regulation and developmental control of proline biosynthesis. Plant J 53:11-28

Taylor CF, Paton NW, Lilley KS, Binz PA, Julian RK Jr, Jones AR, Zhu W, Apweiler R, Aebersold R, Deutsch EW, Dunn MJ, Heck AJ, Leitner A, Macht M, Mann M, Martens L, Neubert TA, Patterson SD, Ping P, Seymour SL, Souda P, Tsugita A, Vandekerckhove J, Vondriska TM, Whitelegge JP, Wilkins MR, Xenarios I, Yates JR III, Hermjakob H (2007) The minimum information about a proteomics experiment (MIAPE). Nat Biot 25:887-893

Thomas R, Sinclair TR, Purcell LC, Sneller CH (2004) Crop transformation and the challenge to increase yield potential. Trends Plant Sci 9:70-75

Timperio AM, Egidi MG, Zolla L (2008) Proteomics applied on plant abiotic stresses: role of heat shock proteins (HSP). J Proteomics 71:391-411

Tuberosa R, Salvi S (2004) QTLs and genes for tolerance to abiotic stress in cereals. In: Gupta PK, Varshney RK (eds) Cereal genomics, 1st edn. Springer, Dordrecht, VIII, pp 253-315

Turan S, Cornish K, Kumar S (2012) Salinity tolerance in plants: breeding and genetic engineering. AJCS 6:1337-1348

Valliyodan B, Nguyen HT (2006) Understanding regulatory networks and engineering for enhanced drought tolerance in plants. Curr Opin Plant Biol 9:189-195

van den Berg RA, Hoefsloot HCJ, Westerhuis JA, Smilde AK, van der Werf MJ (2006) Centering, scaling, and transformations: improving the biological information content of metabolomics data. BMC Genomics 7:1-15

Vanderschuren H, Lentz E, Zainuddin I, Gruissem W (2013) Proteomics of model and crop plant species: status, current limitations and strategic advances for crop improvement. J Prot. doi:10.1016/j.jprot.2013.05.036

Vasquez-Robinet C, Mane SP, Ulanov AV, Watkinson JI, Stromberg VK, De Koeyer D, Schafleitner R, Willmot DB, Bonierbale M, Bohnert HJ, Grene R (2008) Physiological and molecular adaptations to drought in Andean potato genotypes. J Exp Bot 59:2109-2123

Verbruggen N, Hermans C (2008) Proline accumulation in plants: a review. Amino Acids 35:753-759

Verslues PE, Agarwal M, Katiyar-Agarwal S, Zhu J, Zhu JK (2006) Methods and concepts in quantifying resistance to drought, salt and freezing, abiotic stresses that affect plant water status. Plant J 45:523-539 
Villas-Bôas SG, Mas S, Åkesson M, Smedsgaard J, Nielsen J (2004) Mass spectrometry in metabolome analysis. Mass Spec Rev 24:613-646

Vogt T (2010) Phenylpropanoid biosynthesis. Mol Plant 3:2-20

Wang W, Vinocur B, Altman A (2003) Plant responses to drought, salinity and extreme temperatures: towards genetic engineering for stress tolerance. Planta 218:1-14

Wang W, Vinocur B, Shoseyov O, Altman A (2004) Role of plant heat-shock proteins and molecular chaperones in the abiotic stress response. Trends Plant Sci 9:244-252

Wang GP, Zhang XY, Li F, Luo Y, Wang W (2010) Over accumulation of glycine betaine enhances tolerance to drought and heat stress in wheat leaves in the protection of photosynthesis. Photosynthetica 48:117-126

Waters ER, Lee GJ, Vierling E (1996) Evolution, structure and function of the small heat shock proteins in plants. J Exp Bot 47:325-338

Weckwerth W, Kahl G (eds) (2013) The handbook of plant metabolomics. Wiley-Blackwell, Weinheim

Wendelboe-Nelson C, Morris PC (2012) Proteins linked to drought tolerance revealed by DIGE analysis of drought resistant and susceptible barley varieties. Proteomics 12:3374-3385

Widodo, Patterson JH, Newbigin E, Tester M, Bacic A, Roessner U (2009) Metabolic responses to salt stress of barley (Hordeum vulgare L.) cultivars, Sahara and Clipper, which differ in salinity tolerance. J Exp Bot 60:4089-4103

Witt S, Galicia L, Lisec J, Cairns J, Tiessen A, Araus JL, PalaciosRojas N, Fernie AR (2012) Metabolic and phenotypic responses of greenhouse-grown maize hybrids to experimentally controlled drought stress. Mol Plant 5:401-417

Witzel K, Weidner A, Surabhi GK, Börner A, Mock HP (2009) Salt stress-induced alterations in the root proteome of barley genotypes with contrasting response towards salinity. J Exp Bot 60:3545-3557
Wu W, Zhang Q, Zhu Y, Lam HM, Cai Z, Guo D (2008) Comparative metabolic profiling reveals secondary metabolites correlated with soybean salt tolerance. J Agric Food Chem 56: 11132-11138

Yang X, Liang Z, Wen X, Lu C (2008) Genetic engineering of the biosynthesis of glycine betaine leads to increased tolerance of photosynthesis to salt stress in transgenic tobacco plants. Plant Mol Biol 66:73-86

Yates JR, Ruse CI, Nakorchevsky A (2009) Proteomics by mass spectrometry: approaches, advances, and applications. Annu Rev Biomed Eng 11:49-79

Yuan JS, Galbraith DW, Dai SY, Griffin P, Stewart CN Jr (2008) Plant systems biology comes of age. Trends Plant Sci 13: $165-171$

Yusuf MA, Kumar D, Rajwanshi R, Strasser RJ, Tsimilli-Michael M, Govindjee Sarin NB (2010) Overexpression of $\gamma$-tocopherol methyl transferase gene in transgenic Brassica juncea plants alleviates abiotic stress: physiological and chlorophyll a fluorescence measurements. Biochim Biophys Acta 1797:1428-1438

Zhang W, Seki M, Furusaki S (1997) Effect of temperature and its shift on growth and anthocyanin production in suspension cultures of strawberry cells. Plant Sci 127:207-214

Zhang XY, Liang C, Wang GP, Luo Y, Wang W (2010) The protection of wheat plasma membrane under cold stress by glycine betaine overproduction. Biol Plant 54:83-88

Zhu B, Su J, Chang M, Verma DPS, Fan YL, Wu R (1998) Overexpression of a $\Delta^{1}$-pyrroline-5-carboxylate synthetase gene and analysis of tolerance to water- and salt-stress in transgenic rice. Plant Sci 139:41-48

Zlatev ZS, Lidon FC, Ramalho JC, Yordanov IT (2006) Comparison of resistance to drought of three bean cultivars. Biol Plant 50:389-394 